\title{
Shades of blue: non-invasive spectroscopic investigations of Maya blue pigments. From laboratory mock-ups to Mesoamerican codices
}

\author{
Chiara Grazia ${ }^{1,2}$, David Buti ${ }^{3 *}$ (D) Anna Amat ${ }^{2}$, Francesca Rosi ${ }^{2}$, Aldo Romani ${ }^{1,2}$, Davide Domenici ${ }^{4}$, \\ Antonio Sgamellotti ${ }^{1,2}$ and Costanza Miliani $2^{*}$
}

\begin{abstract}
Maya blue is a hybrid pigment where an organic component, indigo, is incorporated in a porous clay. Despite its widespread use in the Mesoamerican artistic production and numerous studies devoted to understand the type of interactions between indigo and the host framework, its technology has not been completely unravelled yet. In this study portable non-invasive UV-vis reflection spectroscopy is proposed as a robust method for in situ investigation of Maya blue pigments. Laboratory mock-ups of powder Maya blue have been prepared employing different synthesis procedures (varying the nature of: clays, indigo-clay ratios, heating temperatures and time). The goodness of the prepared Maya blue samples - namely the occurrence of indigo-clay interactions-have been probed by micro-Raman spectroscopy and related UV-vis spectral markers have been identified. DFT calculations as well have been performed to deeply explain UV-vis profiles. The set of spectral markers have been finally exploited to interpret spectra recorded on Mesoamerican pictorial codices, through a multi-technique approach based on exploring the UV-Vis properties of the blue paint supported by the FT-IR vibrational study of the inorganic clays. The characterization of blue colours on pre-Hispanic and colonial Mesoamerican codices contribute to a better understanding of the compositional variability of these painting materials and to point out the existence of different technological traditions of colour preparation in ancient Mesoamerica.
\end{abstract}

Keywords: Maya blue, Organic-inorganic hybrid pigment, Indigo-clay interactions, Host framework, UV-vis reflection spectroscopy, DFT calculations, Mesoamerican codices

\section{Introduction}

Mesoamerican codices represent the cultural legacy of pre-Hispanic indigenous people who recorded historical, religious, calendrical, and astronomical information using colourful images and logophonetic writing. Only a small part [namely 13 pre-Hispanic codices mostly dated to the Late Postclassic Period (AD 1250-1521)] of the Mesoamerican library holdings survived the ravages of

\footnotetext{
*Correspondence: david.buti@smk.dk; costanza.miliani@cnr.it

${ }^{2}$ CNR-ISTM (Istituto CNR di Scienze e Tecnologie Molecolari), Via Elce di

Sotto 8, 06123 Perugia, Italy

${ }^{3}$ CATS, Statens Museum for Kunst, Sølvgade 48-50, 1307 Copenhagen K, Denmark

Full list of author information is available at the end of the article
}

time as well as the destructions brought by the Spanish conquest and the subsequent campaigns of extirpation of idolatry.

In the last years, non-invasive in situ spectroscopic techniques [1] allowed to study ancient Mesoamerican codices (not only pre-Hispanic but also colonial) in view of their capability to yield information about the materials composition and overall preserving the integrity of these fragile and valuable artefacts [2-14] for which any sampling and transportation are absolutely unthinkable.

The final aim of this study is to explore beyond the limits of today's knowledge of Mesoamerican codices paint technology and to provide material science and art-historical insight by interpreting data recorded through 
a non-invasive multi-technique approach on Maya blue paints from 13 codices (eight pre-colonial and five colonial).

In order to optimize the spectral interpretation and thus maximizing the information of this non-invasive study, in situ data were necessarily compared with results from reference samples as well as interpreted taking into account the wide, vividly debated and sometime also controversial literature on Maya blue.

Maya blue is the well-known hybrid pigment that can be considered as a precursor of modern nanocomposite materials, in which an organic guest, indigo, is incorporated in an inorganic porous host framework, providing a stable and long-standing pigment.

In ancient Mesoamerica indigo (xiuhquilitl in Náhuatl, the language of the Aztecs; añil in modern Spanish) was extracted from the plant Indigofera suffructicosa $[15,16]$ with a process described in two early colonial Mexican sources (the Florentine Codex, also known as Historia General de las Cosas de Nueva España, written by Fray Bernardino de Sahagún [17], and Historia Natural de Nueva España by Francisco Hernandez [18]). The historical sources didn't mention the process of producing Maya blue; nevertheless, recent studies proposed that the Náhuatl term texotli could refer to a blue hybrid organic-inorganic colour [19]. After considerable efforts, the mystery concerning composition and synthetic manufacture of Maya blue was solved in the 1960s. The remarkable stability of Maya blue had led to the conclusion that it was an entirely inorganic pigment, identified by Gettens as palygorskite, a white clay [20]. The presence of an organic dye, responsible for the blue colour, in addition to the clay was first hypothesized by Shepard in 1962 [21]. Few years later Van Olphen finally succeeded in producing a stable blue pigment, resembling Maya blue, by mixing and heating indigo with either palygorskite or sepiolite, both being fibrous clays with a tunnel structure [22]. Palygorskite is a magnesium aluminium phyllosilicate with ideal composition $\mathrm{Si}_{8} \mathrm{O}_{20}\left(\mathrm{Al}_{2} \mathrm{Mg}_{2}\right)$ $(\mathrm{OH})_{2}\left(\mathrm{OH}_{2}\right)_{4} \cdot 4 \mathrm{H}_{2} \mathrm{O}$. Zeolite-like channels running along the fibres are filled by weakly bound, non-structural (zeolitic) water, while magnesium and aluminium cations complete their coordination with tightly bound water molecules (structural water) [23]. In sepiolite, a complex magnesium silicate $\left(\mathrm{Si}_{12} \mathrm{O}_{30} \mathrm{Mg}_{8}(\mathrm{OH})_{4}\left(\mathrm{OH}_{2}\right)_{4}\left(\mathrm{H}_{2} \mathrm{O}\right)_{8}\right)$, the structure defines channels of $10.6 \times 3.7 \AA$ dimensions, wider with respect to palygorskite $(6.4 \times 3.7 \AA)$ [24].

Several spectroscopic and computational studies were devoted to unveil the main location of indigo in the clay framework and to identify the functional groups involved in the interaction which to date are still controversial [25]. Hubbard et al. [26] suggested the occurrence of hydrogen bonds between $\mathrm{C}=\mathrm{O}$ and $\mathrm{N}-\mathrm{H}$ groups of indigo with edge silanol units of the clay, preventing the entrance of the colourant molecules in the channels. Chiari et al. [27] proposed that indigo can fit into the channels of palygorskite, or the external grooves [28] forming hydrogen bonds with structural water of the clay (only through its $\mathrm{CO}$ groups, with the $\mathrm{NH}$ groups remaining free). Another model involves interactions with $\mathrm{Al}^{3+}$ or $\mathrm{Mg}^{2+}$ ions substituting $\mathrm{Si}$ in the crystal lattice with or without coordinated $\mathrm{H}_{2} \mathrm{O}[29,30]$. The heating treatment, inducing the removal of zeolitic water, is always reported as necessary for the indigo molecules to fill the channels $[28,29]$.

On the basis of the wide literature, UV-Vis and Raman can provide valuable information on the effect of Maya blue synthesis conditions on its colour [31-35].

In the present paper a detailed study of specifically conceived reference samples was carried out in order to define UV-vis spectral markers for the non-invasive characterization of Maya blue on real artworks. The UVVis study on reference samples was supported by colorimetry and DFT (density functional theory) calculations. Micro-Raman spectroscopy was performed on the reference materials to control the quality of the synthesized blue samples (i.e. the formation of indigo-clay interactions upon heating) on the basis of literature data [33, 36]. The non-invasive multi-technique approach carried out in situ on the ancient codices was based on UV-Vis supported by FT-IR (Fourier-transform infrared) spectroscopy in reflection mode and colorimetry.

\section{Materials and methods}

According to the literature [22, 37, 38], the Maya blue pigment can be produced (i) by adding the dye from a solution (containing indoxylacetate or indigo by vat-dying) to the clays (palygorskite or sepiolite) or (ii) by mixing the powdered components and heating the mixture. It is generally reported that $1 \mathrm{wt} \%$ is the "optimum" amount of indigo used to prepare genuine Maya blue pigment [32]. However, in our study we have also synthesized laboratory mock-ups including a wider range of indigo loadings (specifically 0.3 and $5 \mathrm{wt} \%$ ) to evaluate the sensitivity and defining the spectral markers and colorimetric properties for Maya blue on models with the aim of interpreting non-invasive in situ results.

In this work reference samples of palygorskite-based and sepiolite-based Maya blue were prepared by ball milling (10 min at a frequency of $15 \mathrm{~Hz}$ ) weighted mixtures of synthetic indigo from Sigma-Aldrich and two types of clay from Kremer (i.e. sepiolite cat. nr. 58945, palygorskite cat. nr. 58903). Particle size (determined by laser diffraction and expressed as average volume distribution) of palygorskite and sepiolite (after grinding) are $12.4 \mu \mathrm{m}$ and $10.2 \mu \mathrm{m}$, respectively. The samples 
were heated in furnace for $24 \mathrm{~h}$ at $130,160,180{ }^{\circ} \mathrm{C}$. To evaluate the effect of a high temperature heating phase, a further Maya blue specimen heated at $230{ }^{\circ} \mathrm{C}$ was prepared. Its spectral features have been compared with those of real Maya blue paints and discussed only in the "Case studies" section. Selected samples were purified through Soxhlet extraction in acetone in order to remove the weakly interacting dye.

In situ UV-vis reflection, steady-state photoluminescence and FT-IR measurements on Mesoamerican codices were carried out with instruments and set-ups described in references [2, 4-7] while the laboratory apparatus and conditions employed for the characterization of mock-ups are described hereinafter.

Raman analyses were carried out with a Bruker Senterra system with a thermoelectrically cooled charged-coupled device (CCD) detector. Raman spectra were recorded by focusing a $785 \mathrm{~nm}$ laser beam through a $50 \times$ and $100 \times$ Olympus objectives. 400 lines $/ \mathrm{mm}$ gratings and 1200 lines $/ \mathrm{mm}$ gratings were used. The laser power at the sample was kept between 1 and $25 \mathrm{~mW}$ with an acquisition time between 10 and $60 \mathrm{~s}$ for each spot collecting 1 to 5 accumulations.

The optical properties of the samples in the powder form were analysed 14 months after the synthesis. The surface of sample powders was gently pressed and flattened before performing the measurements.

A compact portable instrument designed for non-invasive in situ diagnostic, developed within the European FP7 CHARISMA project for reflection and steady-state photoluminescence (PL) measurements, was used. A multi-furcated fibre optic system (Avantes, NL) directs the excitation sources to the surface and collects both the reflected and emitted light with an optical layout $21^{\circ} / 21^{\circ}$. For reflection measurements the sample illumination is provided by a deuterium-halogen lamp (Avalight-DHc, Avantes, NL). A highly sensitive CCD spectrometer (Avaspec-2048 USB2, Avantes, NL; 200-1100 nm range, spectral resolution $8 \mathrm{~nm}$ ) and an InGaAs TE cooled AvaSpec-NIR256-1.7TEC (950-1650 nm range, spectral resolution $24 \mathrm{~nm}$ ) detect the reflected light. Calibration was performed by using a white Spectralon (Labsphere), unless otherwise stated. The reflectance profiles collected by the two spectrometers have been scaled/offset to match in the 950-1000 nm range; the resulting spectra have been interpolated to equally spaced points in the 200-1650 nm range. First derivative (smoothed using a Savitzky-Golay algorithm, polynomial order 2, filter size 15 points) was performed to homogeneously define the position of absorption bands. The spot size at the sample position is approximately $1.8 \mathrm{~mm}^{2}$.

The absorption spectra in solution were recorded with a Perkin- Elmer Lambda 800 spectrophotometer.
A portable spectrophotometer CM-700d (di: $8^{\circ}$ geometry, Konica Minolta) was used for colorimetry. CIE L"a"b* values were calculated for D65 illuminant, $10^{\circ}$ observer.

DFT and TDDFT (time-dependent density functional theory) calculations have been performed using the B3LYP hybrid functional [39-42] and 6-31++G*: basis set. The solvation effects have been taken into account by means of the conductor-like polarizable continuum model CPCM [43, 44]. Molecular orbitals, electronic distributions and transitions have been computed at the same level of theory. For the lowest 60 singlet-singlet transitions computed, transition energies and oscillator strengths have been interpolated using a Gaussian convolution of 0.20. All calculations have been carried out with the Gaussian09 suite [45].

\section{Results}

Preliminary characterization of Maya blue reference samples

Pre-resonance micro-Raman analysis of palygorskitebased and sepiolite-based Maya blue replicas were aimed at investigating dye-clay interactions as function of differences in weight ratio (indigo-clay), temperature and heating time. A detailed discussion of the Raman results is reported in the electronic supplementary information, following the Raman spectral markers identified and assigned by del Río et al. [36].

The outcomes of the Raman analysis are the following: (i) the unheated mixture of indigo and palygorskite shows signals compatible with those of the pure dye and spectral changes ascribable to the dye-clay interaction are visible only after heating; (ii) $1 \mathrm{~h}$ thermal treatment is not sufficient for a complete indigo-palygorskite interaction independently from the temperature; (iii) diversely from palygorskite-adduct, the interaction between sepiolite and indigo occurs already after grinding even prior the thermal treatment; (iv) the spectral features indicating indigo interacting with the inorganic matrix can be observed independently from the initial concentration; (v) an initial high concentration of indigo (5 wt\%) leads to a hybrid pigment with free molecules of the dye independently of the type of clay; (vi) the spectral behaviour of the indigo-sepiolite adduct is intermediate between the pure dye and the palygorskite-based Maya blue indicating a different interaction between the two components.

UV-vis spectral markers and effect of synthesis parameters on the optical properties of palygorskite-based and sepiolite-based hybrids UV-Vis reflection properties of palygorskite-based hybrids Indigo, or indigotin (2,2'-bis(2,3-dihydro-3-oxoindolyliden), is an organic dye which owes its blue colour to the presence of a doubly cross-conjugated system 
of two electron donor groups (the amino groups) and two electron acceptors groups (the carbonyl groups). In solution the molecule exhibits a positive solvatochromism (ranging from $603 \mathrm{~nm}$ in chloroform to $611 \mathrm{~nm}$ in dimethylformamide) [46, 47], and in the solid state the absorption is further red-shifted $(661 \mathrm{~nm})$ as the result of the presence of extended intermolecular hydrogen bonding [34, 48-50], as shown in Figs. 1a and 2a.

The molecule in solution is also characterised by an intense UV band [located at $286 \mathrm{~nm}$ in chloroform and at $288 \mathrm{~nm}$ in dimethylformamide (DMF)], whose relative intensity is higher compared to the main visible band, and by a weak band in the visible range (located at $426 \mathrm{~nm}$ in chloroform and at $444 \mathrm{~nm}$ in dimethylformamide). The UV band can be seen in the absorption spectrum of solid-state indigo although, conversely to the solution, its relative intensity is lower compared to the band at $661 \mathrm{~nm}$ (Fig. 1a).

Consistently, the reflectance spectrum of the unheated mixture of indigo (1 wt\%) and palygorskite exhibits a maximum at $430 \mathrm{~nm}$ (shifting from 460 to $420 \mathrm{~nm}$ by varying the concentration of indigo, as shown in Figs. 2a, c, d) and a broad absorption band between 500 and $730 \mathrm{~nm}$ $\left(\lambda_{\max }\right.$ at $656-657 \mathrm{~nm}$ in highly diluted samples and about $635 \mathrm{~nm}$ at higher indigo concentration, when the colour saturation results in a very high absorption intensity).
The appearance of weak shoulders at about 545 and $600 \mathrm{~nm}$ in the broad footing of the main absorption band (Fig. 2a) has been assigned to the presence of small clusters of indigo molecules with restricted intermolecular hydrogen bonding that form as a result of grinding [24, 34]. These bands, which resemble those of indigo in solution (see Fig. 1a), are also visible in spectral profiles of crystalline or amorphous thin films of indigo $[48,49,51]$.

A supplementary band at about $880 \mathrm{~nm}$ is clearly visible at higher indigo loadings (5 wt\%, Fig. 2d). Palygorskite has no significant absorption in the visible range and in the $\mathrm{UV}$ region exhibits a band at $257 \mathrm{~nm}$ related to $\mathrm{Si}-\mathrm{O}$ [52]; additionally, in the NIR (near infrared) range it exhibits a band in the range 1350-1550 nm (not shown) attributed to the first overtone of the hydroxyl stretching mode [53].

As expected, in the $\mathrm{L}^{*} \mathrm{a}^{*} \mathrm{~b}$ * space all unheated mixtures with palygorskite are situated in the blue zone, and by decreasing the concentration of indigo (from $5 \mathrm{wt} \%$ to $0.3 \mathrm{wt} \%$ ) the $\mathrm{a}^{*}$ value decreases and the $\mathrm{b}^{*}$ value increases, leading to a displacement toward a more green/yellow zone (Fig. 2b).

Relevant spectral changes induced by heating at $130{ }^{\circ} \mathrm{C}$ are displayed in Fig. 2a, c, d (grey lines). Firstly, a decrease of reflectance is observed in all the investigated range. Moreover, as already described in the literature [34,50], the shape of the dominant band becomes more symmetrical and sharper on the short
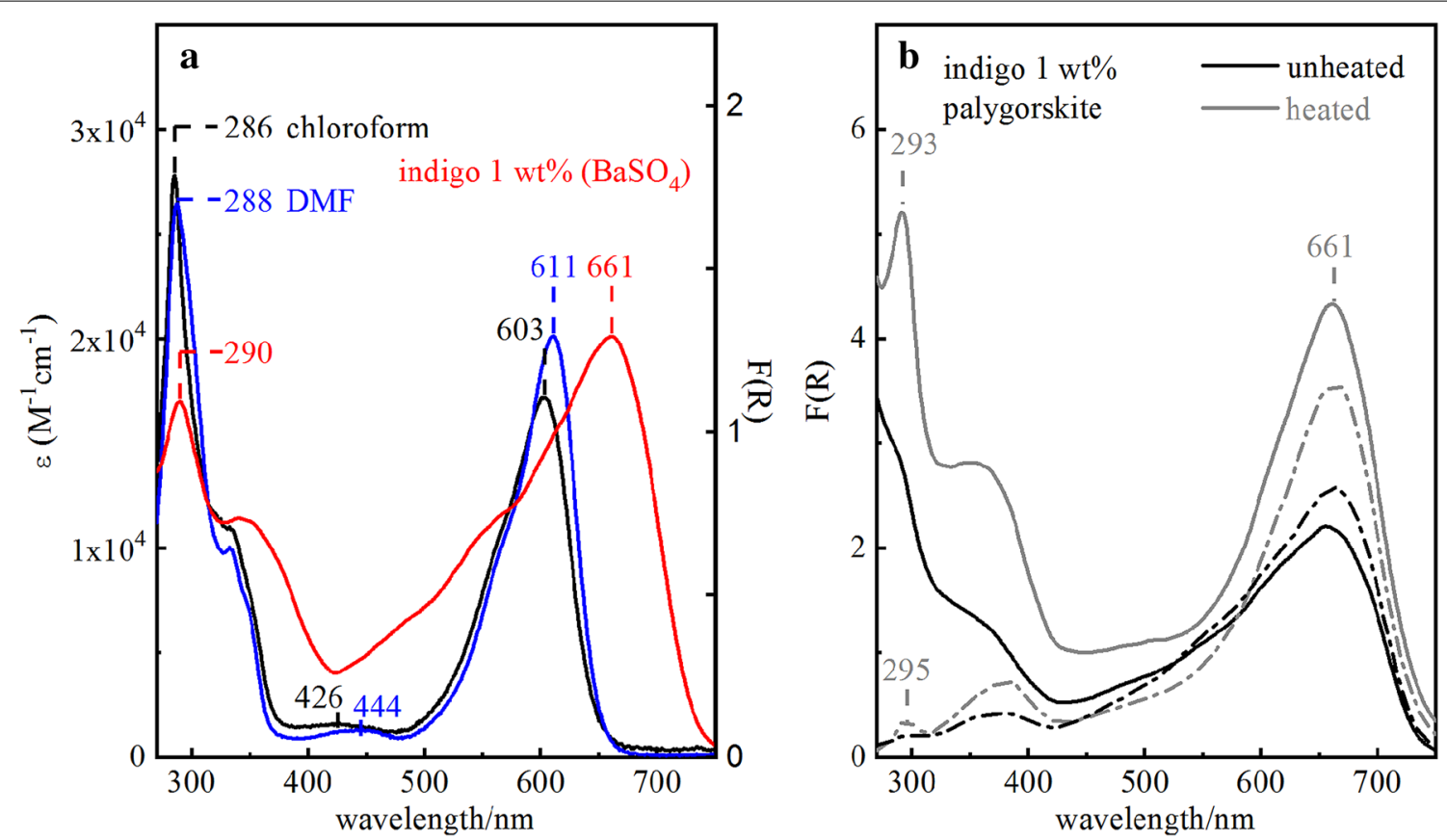

Fig. 1 a Absorption of synthetic indigo in chloroform $\left(1.3 \times 10^{-5} \mathrm{M}\right)$ and dimethylformamide $\left(2.1 \times 10^{-5} \mathrm{M}\right)$; Kubelka-Munk spectra of solid indigo (1 wt\%) dispersed in $\mathrm{BaSO}_{4}$ (calibration performed with $\mathrm{BaSO}_{4}$ ). $\mathbf{b}$ Kubelka-Munk spectra of unheated and heated $24 \mathrm{~h}$ at $130{ }^{\circ} \mathrm{C}$ indigo 1 wt $\%$ / palygorskite mixture. Reference materials for calibration: Spectralon (solid lines), palygorskite (dash-dotted lines) 

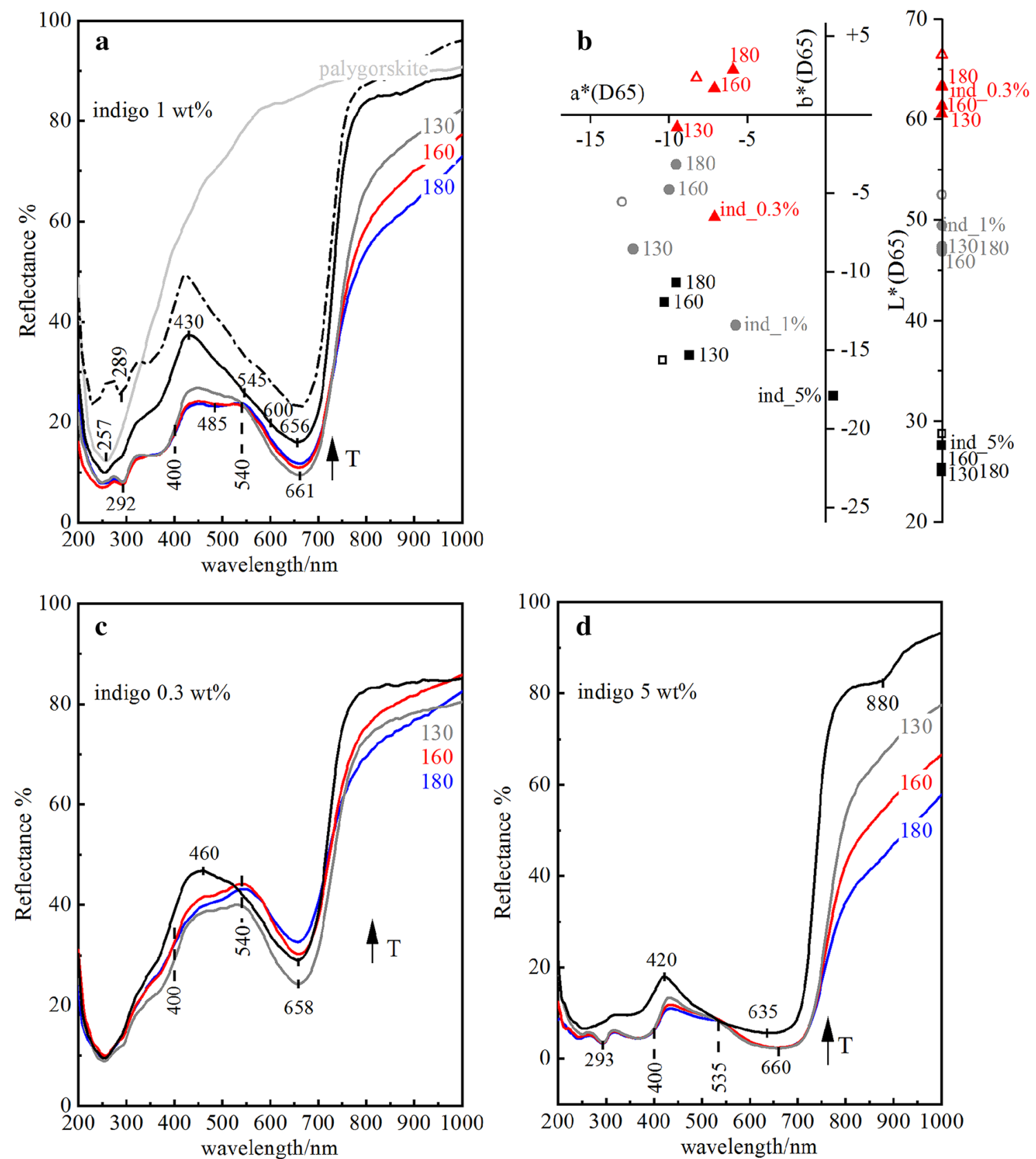

Fig. 2 a Reflectance spectra of unheated (black line) and heated $\left(24 \mathrm{~h}\right.$ at $130{ }^{\circ} \mathrm{C}, 160^{\circ} \mathrm{C}$ and $180^{\circ} \mathrm{C}$ ) indigo-palygorskite mixtures (indigo $1 \mathrm{wt} \%$ ). Reflectance spectra of solid indigo (1 wt\%) dispersed in $\mathrm{BaSO}_{4}$ (calibration performed with $\mathrm{BaSO}_{4}$ ) is also reported for comparison (dash-dotted black line). $\mathbf{b}$ Projection in the $\mathrm{a}^{*} \mathrm{~b}^{*}$ space of the colorimetric measurements and $\mathrm{L}^{*}$ values of the samples before and after heating (empty symbols: samples heated at $130^{\circ} \mathrm{C}$ after the Soxhlet extraction; ind: indigo). c Reflectance spectra of unheated (black lines) and heated $\left(24 \mathrm{~h}\right.$ at $130^{\circ} \mathrm{C}, 160^{\circ} \mathrm{C}$ and $180^{\circ} \mathrm{C}$ ) indigo-palygorskite mixtures (indigo $0.3 \mathrm{wt} \%$ ). $\mathbf{d}$ Reflectance spectra of unheated (black lines) and heated $\left(24 \mathrm{~h}\right.$ at $130^{\circ} \mathrm{C}, 160^{\circ} \mathrm{C}$ and $180^{\circ} \mathrm{C}$ ) indigo-palygorskite mixtures (indigo $5 \mathrm{wt} \%$ )

wavelength side upon heating, although the transition energy is almost retained $\left(\lambda_{\max } 658,661\right.$ and $660 \mathrm{~nm}$ for $0.3,1$ and $5 \mathrm{wt} \%$ indigo, respectively). In addition, the absorption edge appears red-shifted (up to $25 \mathrm{~nm}$, when taking into account the position of the inflection point).
According to the literature [30,36,54], heating induces the disaggregation of crystalline solid-state clusters while indigo diffuses and interacts with the clay. Therefore, since the weak feature at $880 \mathrm{~nm}$ (visible at high indigo loadings, Fig. 2d) disappears upon heating, it can be tentatively ascribed to polycrystalline indigo. 
A supplementary observation suitable for diagnostic purposes is that the heating process induces a remarkable change of reflectance profile in the UV region, as shown in Fig. 2a. Indeed, an absorption band at 292-294 $\mathrm{nm}$ is detected, although it appears as a weak shoulder when the concentration of indigo is less than $1 \mathrm{wt} \%$ (Fig. 2c). This feature is also visible in the spectra of indigo in diluted solution (Fig. 1a) and with a lesser extent (and with a broader shape) at higher dye concentrations, when the coexistence of monomeric and dimeric indigo is reported to occur [55]; an absorption band in the UV region, although weak, is also detected when a low amount of solid indigo is finely dispersed in barium sulphate (Fig. 2a). The UV feature in the reflectance spectrum of indigo-palygorskite mixtures prior to heating could be hidden by the absorption of the clay in this spectral region, but its appearance only after the heating treatment (as confirmed by using palygorskite to calibrate the spectra, as shown in Fig. 1b) provides a clear indication of a change in the electronic structure of the dye due to the interaction with the clay. The interaction between indigo and clay seems to have a little effect on the energy of the UV transition if compared to the pronounced bathocromic shift observed in the visible band when passing from solution to solid-state. This evidence can be explained by taking into account the differences in the charge distribution of the molecular orbitals involved in the two transitions, as it will be discussed in "DFT calculations" section.

When a short thermal treatment is applied, namely for $1 \mathrm{~h}$, colour modification is mainly related to the decrease of the $\mathrm{a}^{*}$ value (spectrum not shown), indicating that even if indigo not bound or partially bound is still present, the interaction with the clay is strong and causes a initial change of the tonality toward more greenish hues. A prolonged $(24 \mathrm{~h})$ heating treatment at $130{ }^{\circ} \mathrm{C}$ induces both a decrease of the $\mathrm{a}^{*}$ value (more marked at higher indigo loadings) and an increase of the $b^{*}$ value which simultaneously indicate a change of colour towards a more green/yellow zone.

Similar variations of colour by changing the concentration of indigo are described in references [30, 34]. Reinen et al. claim that in Maya blue "indigo colour centres are chemically bonded to the solid matrix and lying preferentially isolated from each other" [34]. They explain the influence of the concentration of indigo on colour as the result of a limited capacity of the host lattice for binding the guest molecules; at high indigo loadings unreacted clusters of indigo molecules on the surface of the clay are therefore responsible for the blue hue. Accordingly, the (at least partial) removal of excess indigo by Soxhlet extraction performed on palygorskite-based hybrids obtained by heating at $130{ }^{\circ} \mathrm{C}$ results in a colour change towards more greenish hues (empty symbols in Fig. 2b). In the case of the replica with a high concentration of indigo (5 wt\%) micro-Raman spectroscopy detected indigo not bound or partially bound (Additional file 1: Fig. S1), and the colour displacement after Soxhlet extraction mainly results from a lowering of the $\mathrm{a}^{*}$ value, which again could be considered the main parameter which indicates the interaction dye-clay.

As a further step, the influence of the thermal treatment temperature was also evaluated. At $1 \mathrm{w} \%$ indigo loadings (Fig. 2a) by increasing the heating temperature (namely 160 and $180{ }^{\circ} \mathrm{C}$ ) the reflectance profiles exhibit a progressive decrease of intensity of indigo visible band and an increase of absorption in the range $400-540 \mathrm{~nm}$, resulting in the appearance of a weak absorption band at about $485 \mathrm{~nm}$. Similar spectral modifications are observed at $0.3 \mathrm{wt} \%$ dye loadings (Fig. 3a), affecting both indigo visible band and the range $400-540 \mathrm{~nm}$, in which a decrease of the ratio $R(430 \mathrm{~nm}) / R(540 \mathrm{~nm})$ is noticed. At $5 \mathrm{wt} \%$ indigo loadings (Fig. 2d) the changes of reflectance profiles are of a kind, although less marked.

The effect of the further heating temperature on colour was also evaluated. A red colour shift (increase of the $\mathrm{a}^{*}$ value) is observed in samples with low concentration of indigo (0.3 and $1 \mathrm{wt} \%)$, while at $5 \mathrm{wt} \%$ indigo loadings the opposite trend is observed, possibly indicating that higher temperatures are required to complete the formation of the hybrid in presence of a high amount of indigo. Anyway, for all investigated samples the main displacement involves $b^{*}$ value, which increases as the temperature increases, derived from the progressive diminishing of the absorption band of indigo and the concomitant increase of absorption below $540 \mathrm{~nm}$ (Fig. 2).

\section{UV-Vis reflection properties of sepiolite-based hybrids}

Differently to what observed for palygorskite, when mixing indigo and sepiolite pronounced modifications of the reflectance properties with respect to the ones of solid indigo are already observed prior to heating (black line, Fig. 3a, c, d). Specifically, both shape (more symmetrical) and position (blue-shifted, with $\lambda_{\max } 646,644$ and $640 \mathrm{~nm}$ for $0.3,1$ and $5 \mathrm{wt} \%$ indigo, respectively) of the absorption band in the visible region, provide indication that an interaction between indigo and sepiolite begin to form during the grinding phase, as already noticed by Giustetto et al. [24] and confirmed by micro-Raman analysis (Additional file 1: Fig. S2). Evidence that sepiolite can form an adduct with indigo even without heating is also reported in references $[26,38,56]$. It has been explained as the effect of the lower particle size and the wider tunnel dimensions of sepiolite compared to palygorskite. It has to be taken into consideration also the higher mobility of the zeolitic water in sepiolite than in 

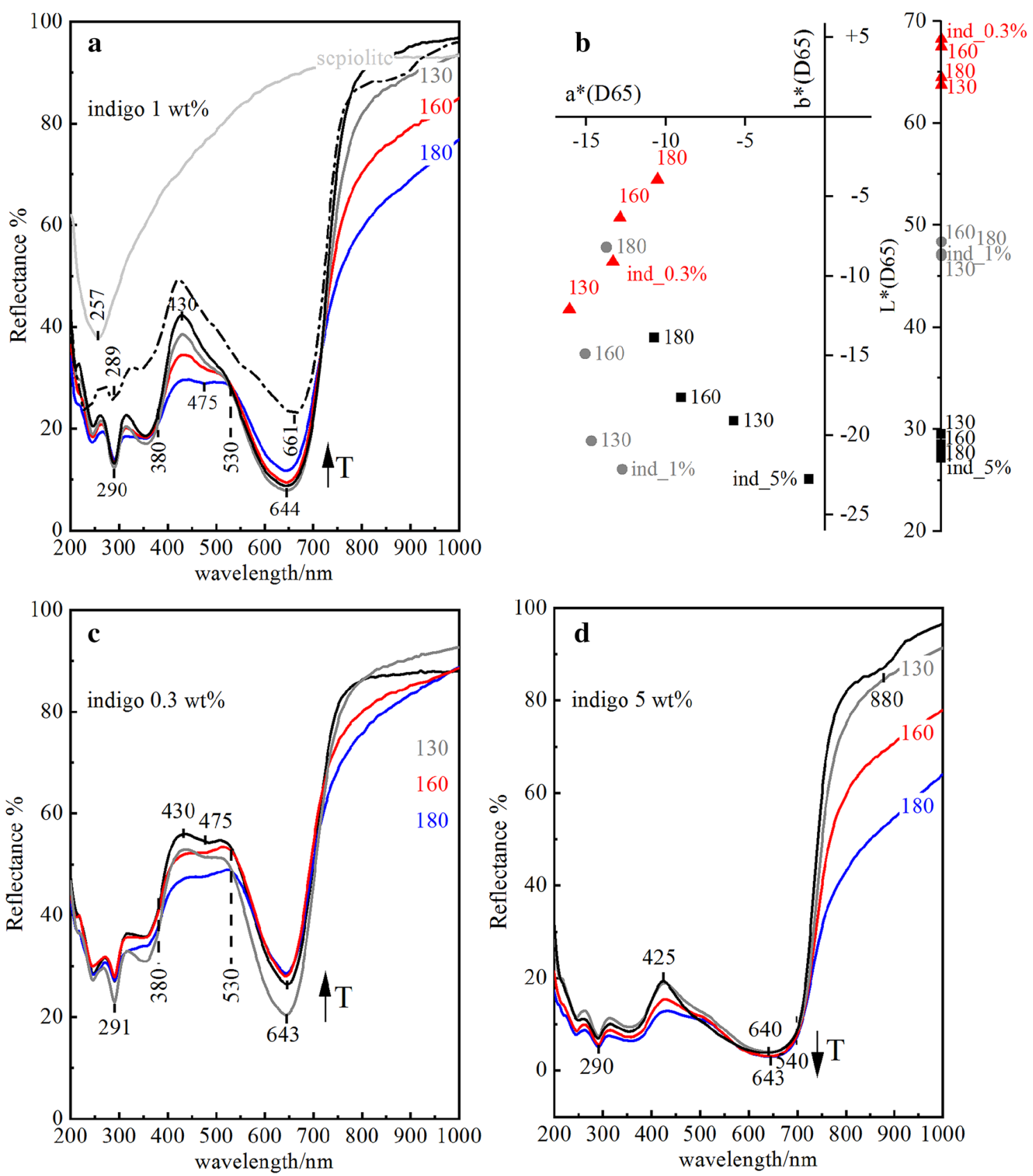

Fig. 3 a Reflectance spectra of unheated (black lines) and heated $\left(24 \mathrm{~h}\right.$ at $130^{\circ} \mathrm{C}, 160^{\circ} \mathrm{C}$ and $180^{\circ} \mathrm{C}$ ) indigo-sepiolite mixtures (indigo $1 \mathrm{wt} \%$ ). Reflectance spectra of solid indigo (1 wt\%) dispersed in $\mathrm{BaSO}_{4}$ (calibration performed with $\mathrm{BaSO}_{4}$ ) is also reported for comparison (dash-dotted black line). $\mathbf{b}$ Projection in the $a^{*} b^{*}$ space of the colorimetric measurements and $L^{*}$ values of the sepiolite-containing samples before and after heating (ind: ind). c Reflectance spectra of unheated (black lines) and heated $\left(24 \mathrm{~h}\right.$ at $130^{\circ} \mathrm{C}, 160^{\circ} \mathrm{C}$ and $180^{\circ} \mathrm{C}$ ) indigo-sepiolite mixtures (indigo $0.3 \mathrm{wt} \%)$. d Reflectance spectra of unheated (black lines) and heated $\left(24 \mathrm{~h}\right.$ at $130^{\circ} \mathrm{C}, 160^{\circ} \mathrm{C}$ and $180^{\circ} \mathrm{C}$ ) indigo-sepiolite mixtures (indigo 5 wt $\%$ )

palygorskite, as suggested by some authors [57]. It may be, at least in part, that indigo replaces zeolitic water even without dehydration by temperature. The energy position of the visible band is found to be close to what reported for amorphous indigo, a disordered array of hydrogen bonded molecules [49]. The shift of the visible band respect to crystalline indigo and palygorskitebased hybrid may be interpreted according to Giustetto et al. $[24,56]$ in term of different indigo-clay interactions: when indigo is intercalated in palygorskite it can be 
linked on both sides of the molecule, while in sepiolite, characterised by larger tunnels, is more likely anchored to the clay framework only on one side. Consistently reflectance spectra exhibit a sharp absorption band in the UV region, slightly blue-shifted $\left(\lambda_{\max } 290-291 \mathrm{~nm}\right)$ with respect to the palygorskite-based adducts and closely resembling the one observed for the molecule in solution. This is indicative of a (at least) partial disaggregation of associated molecules of indigo due to the interaction with the clay.

Heating at $130^{\circ} \mathrm{C}$ has a less striking effect on the reflectance profile, although the position of the visible band slightly shifts $\left(\lambda_{\max } 643,644\right.$ and $643 \mathrm{~nm}$ for $0.3,1$ and 5 $\mathrm{wt} \%$ indigo, respectively). The diffusion of the molecules driven by heating induces an increased interaction with the hosting clay, resulting in the observed increase of absorption. Consistently, in the case of sepiolite (Fig. 3b) the displacement of the colorimetric coordinates is less marked with respect to palygorskite (for a direct comparison see also Additional file 1: Fig. S3a, b). As for palygorskite-based hybrids, the sample containing a low amount of indigo displays the more greenish hue, although in this case a decrease of $b^{*}$ is noticed.

Upon increasing the temperature, similarly to the indigo-palygorskite hybrid system, the reflectance spectra display a decreased intensity of the main absorption band (Fig. 3a) and changes in the range 380-530 nm with the appearance of a weak absorption band at about $475 \mathrm{~nm}$. This is common to samples containing 1 and $0.3 \mathrm{wt} \%$ of indigo. With higher content of indigo ( $5 \mathrm{wt} \%$, Fig. 3d), the main indigo absorption band increases by increasing temperature, possibly indicating an increase of the intercalated indigo. Simultaneously, also the absorbance below $530 \mathrm{~nm}$ increases. In addition, the weak band at $880 \mathrm{~nm}$ is visible in the spectrum of the unheated mixture (black line, Fig. 3d) and similarly to palygorskiteindigo mixtures it disappears after heating.

As for palygorskite-based samples, by increasing the heating temperature the increase of the $a^{*}$ value is noticed in samples with low concentration of indigo (in this case a red-shift is marked only at $0.3 \mathrm{wt} \%$ indigo), while at higher indigo loadings the $\mathrm{a}^{*}$ value decreases, possibly related to a progressive formation of the hybrid.
As already observed the main modification is the increase of the $b^{*}$ value as the temperature increases (Fig. 3b, Additional file 1: Fig. S3).

\section{DFT calculations}

To understand the different behaviour of the UV and visible bands in terms of their electronic properties, TD-DFT (time-dependent density functional theory) calculations have been used (Table 1).

Absorption spectra computed using TD-DFT show a broad maximum in the visible region, see Fig. 4a. As already reported by Amat et al. [58], the lowest energy band computed between the ground $\left(\mathrm{S}_{0}\right)$ and first-excited state $\left(\mathrm{S}_{1}\right)$ in the visible region at $605 \mathrm{~nm}$ is in excellent agreement with the experimental feature measured at $603 \mathrm{~nm}$. This band is formed by a single $\pi$ and $\pi^{*}$ transition between the HOMO (highest occupied molecular orbital) and the LUMO (lowest unoccupied molecular orbital). The HOMO is conjugated through the whole molecule with a big $\pi$ orbital while the excited state (LUMO) shows an antibonding interaction on the CC central bond (Fig. 4b). Both orbitals show a consistent charge density on both the carbonyl oxygen and aminic hydrogen that, as stated before, could be involved in the interaction with the inner channels of the clay.

The calculated band in the UV region (with a shoulder at lower energy) is also in excellent agreement with the experiment (Fig. 4a). The main band $\mathrm{S}_{0}-\mathrm{S}_{10}$ computed at ca. $279 \mathrm{~nm}$ is mainly originated by a transition from the HOMO -1 to the LUMO +1 . The molecular orbital distributions show a $\pi \rightarrow \pi^{*}$ transition where departing state is delocalized over the whole molecule and has an antibonding distribution between the two moieties on the $\mathrm{CC}$ central bond while the arrival state has a not null distribution in the CC central bond (Fig. 4c). Interestingly, it can be noticed that the carbonyl oxygen and aminic hydrogen are much less involved on the transition comparing to the band on the visible region. Indeed charge densities are much more localized in these atoms in the HOMO and LUMO than in the HOMO $-1, \mathrm{LUMO}+1$ as can be seen from Fig. $4 \mathrm{~b}$.

Table 1 Computed TD-DFT transitions of indigo in chloroform and experimental data of indigo in solvent, hybrid palygorskite-based Maya blue (Paly-MB) and sepiolite-based Maya blue (Sep-MB)

\begin{tabular}{|c|c|c|c|c|c|}
\hline & \multicolumn{2}{|l|}{ Theoretical } & \multicolumn{3}{|l|}{ Experimental } \\
\hline & & & \multirow{2}{*}{$\begin{array}{l}\text { Chloroform } \\
\lambda_{\max } / \mathrm{nm}(\mathrm{eV})\end{array}$} & \multirow{2}{*}{$\begin{array}{l}\text { Paly-MB } \\
\lambda_{\max } / \mathrm{nm}(\mathrm{eV})\end{array}$} & \multirow{2}{*}{$\begin{array}{l}\text { Sep-MB } \\
\lambda_{\text {max }} / \mathrm{nm}(\mathrm{eV})\end{array}$} \\
\hline & $\lambda_{\max } / \mathrm{nm}(\mathrm{eV})$ & Composition & & & \\
\hline Visible band & $605(2.05)$ & $H \rightarrow L(75 \%)$ & $603(2.06)$ & $661(1.88)$ & $642(1.93)$ \\
\hline UV band & $279(4.45)$ & $H-1 \rightarrow L+1(87 \%)$ & $286(4.34)$ & $293(4.23)$ & $290(4.28)$ \\
\hline
\end{tabular}




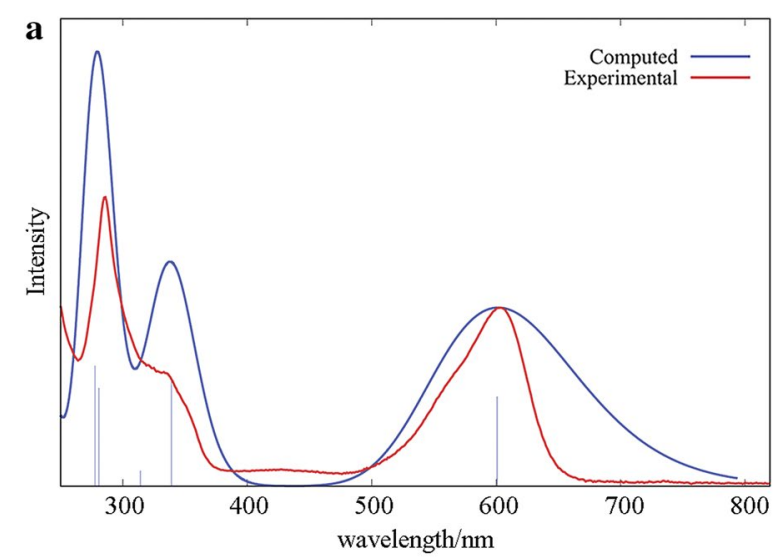

b

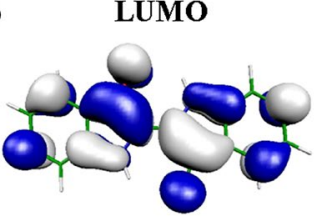

c

LUMO+1

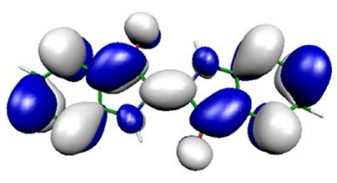

HOMO-1
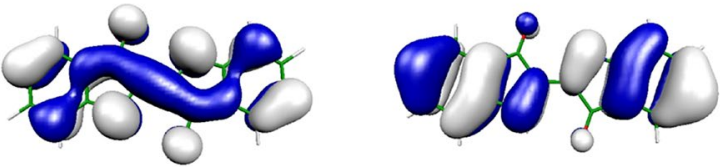

Fig. 4 a Computed vertical excitation for monomeric indigo in chloroform. b HOMO and LUMO MO electronic distribution, involved in the transition in the visible region [58]. c HOMO -1 and LUMO + 1 $\mathrm{MO}$ electronic distribution, involved in the main transition in UV region

To get deeper inside on this issue, the isodensity plots of the change on the electronic distribution of the band in the visible region $\left(\mathrm{S}_{0}-\mathrm{S}_{1}\right)$ and the band and shoulder in the UV region $\left(\mathrm{S}_{0}-\mathrm{S}_{10}\right.$ and $\left.\mathrm{S}_{0}-\mathrm{S}_{6}\right)$ have been computed, see Fig. 5. In the visible region transition, upon excitation a consistent charge transfer from the $\mathrm{N}$ to the $\mathrm{C}=\mathrm{O}^{-}$is observed, both hypothetically involved in the interaction with the clay. The transition computed at $342 \mathrm{~nm}$ (shoulder in the UV region) still shows a charge injection into the $\mathrm{C}=\mathrm{O}^{-}$on the excited state but the charge comes from $\mathrm{NH}$ only to a minor extent. In the main transition in the UV region a clear decrease of the charge injected into $\mathrm{C}=\mathrm{O}^{-}$with respect to the transition at $605 \mathrm{~nm}$ can be noticed.

These evidences are consistent with the fact that, experimentally larger changes on the visible spectral region when passing from the isolated molecule to the clay are retrieved.
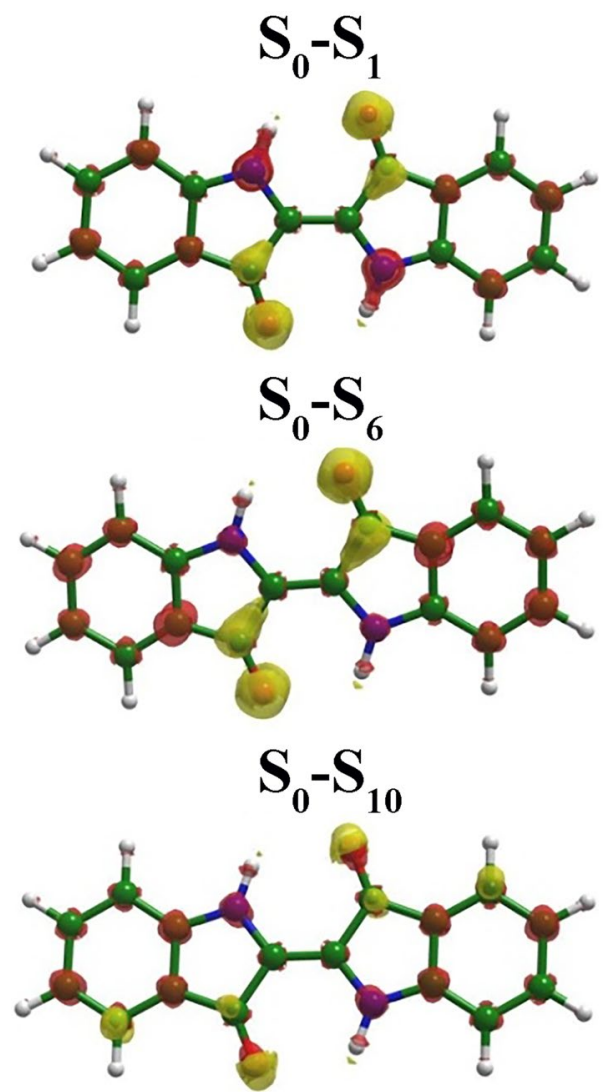

Fig. 5 Isodensity plots of the electron density difference between the ground and $S_{n}(n=1,6,10)$ excited states computed in chloroform. Yellow (red) indicates an increase (decrease) of the electron density upon excitation

\section{Concluding remarks}

On the basis of the whole study on model samples the following results may be summarized and considered for interpreting the non-invasive and in situ results on the Mesoamerican codices.

i. The discrimination among indigo and Maya-blues (both palygorskite-based and sepiolite-based) is possible by observing modification of the visible absorption band and thanks to the increasing of the UV band at about 292-294 and 290-291 nm originated from the interaction of indigo with palygorskite and sepiolite, respectively. The UV region is out of the measuring range of most the instruments, and to the best of our knowledge the reflectance features of palygorskite-based Maya blue in this range are reported only in references [33, 34], although not discussed. 
ii. The UV band can also be profitably exploited for distinguishing unheated indigo-palygorskite mixtures from Maya blue palygorskite-based. The observation of the UV band also suggests the "quasi-monomeric" nature of indigo in the clays framework being present in the spectrum of indigo in solution. The further evidence that the visible band is positioned at comparable energies to what observed in the highly hydrogen bonded solid state indicates that this "quasi-monomeric" indigo can be linked on both sides of the molecule with the clay. Accordingly, DFT calculations highlight that the electron density difference between the ground and excited states of the visible and the UV bands show a different behaviour of the charge transfer. In particular, the carbonylic oxygen and the aminic hydrogen are much more involved in the visible transition compared to the UV band.

iii. The study also reveals that it is possible to distinguish, by exploring the optical properties in the $\mathrm{UV}-\mathrm{Vis}$ range, when indigo is in palygorskitebased or sepiolite-based Maya blues. The visible absorption band is blue-shifted in the indigo-sepiolite hybrid with respect to the indigo-palygorskite analogous of about $20 \mathrm{~nm}$, whilst the UV band (as demonstrated also by the DFT calculation) being less sensitive to the type of dye-clay interaction is placed at similar wavelengths. The different behaviour has been explained by Giustetto et al. $[24,56]$ by taking into account the different indigo-clay interactions: in palygorskite indigo can be linked on both sides of the molecule, while in sepiolite only on one side. In the latter the intercalation starts during the grinding phase as indicated also by the presence of the UV band before the heating.

iv. The effect of the synthesis conditions (either initial indigo concentration or heating temperature), considered for simulating realistic UV-Vis reflection spectra in order to optimize the spectral interpretation with those non-invasively recorded in situ on the codices, strongly affected the final optical properties of the samples.

By increasing the concentration of indigo in the initial mixture while keeping fixed temperature and duration of the thermal treatment, the molecules, partially located on the surface of the clay (interacting with its framework), will impart a blue colour to the hybrid.

The marked increase of absorption in the 400$550 \mathrm{~nm}$ range as the temperature increases can be interpreted in terms of: (a) a temperature-driven conversion of indigo into different species absorbing below $540 \mathrm{~nm}$ (i.e. dehydroindigo) and (b) the shift of a chemical equilibrium between two types of indigo molecules, differentiating themselves as the effect of the chemical environment.

In brief, (a) according to the model proposed by Doménech et al. various indigoid molecules, besides indigo, are reported to coexist in the clay matrix-externally bound or internally incorporated in the channels-and among them dehydroindigo is favored by the increase of temperature $[25,32,59,60]$.

According to the hypothesis (b) the absorption band in the range $400-540 \mathrm{~nm}$, already visible in the spectra of indigo in solution (although weak, as shown in Fig. 1a), could be enhanced in the hybrid as a result of a decrease in the indigo molecular symmetry when the molecules are hydrogen bonded to coordinated water molecules inside the micropores; its intensity would depend on the fraction of interacting molecules which is reported to increase with temperature ([33] and references therein).

To ascertain which one of the two hypotheses is the most plausible one is beyond the scope of this paper, also because this topic has been vividly debated in the literature.

\section{Case studies}

As already mentioned in "Introduction", only 13 pre-Hispanic codices have survived. Those codices are divided into three groups (Borgia group, Mixtec group, Maya group) on the basis of their style, content, and provenance. In particular, eight of them and five early colonial ones were investigated by the mobile laboratory MOLAB and the results of some of these non-invasive analytical campaigns have been published in references [2-7]. Detailed information about the codices is reported in Table 2.

In the following, we report a comprehensive survey of the results obtained on blue areas of the codices (some details of the codices pages are shown in Fig. 6), with a focus on the use of indigo dye and indigo-based hybrid pigment.

Due to logistical constraints, in terms of accessibility to the codices and their handling, a careful selection of representative areas of the various colours for each codex was carried out before the in situ analytical campaign. The selection, carried out by a team of archaeologists and codices' experts, was based on iconographic reasons as well as on considerations based on the naked eye observation. As far as the blue paint is concerned, measurements were carried out on more than one point per blue area. However, for clarity, only one representative spectrum for typology has been reported in this paper (Fig. 7).

UV-vis reflectance spectral markers, experimentally and theoretically discussed in the previous sections, 


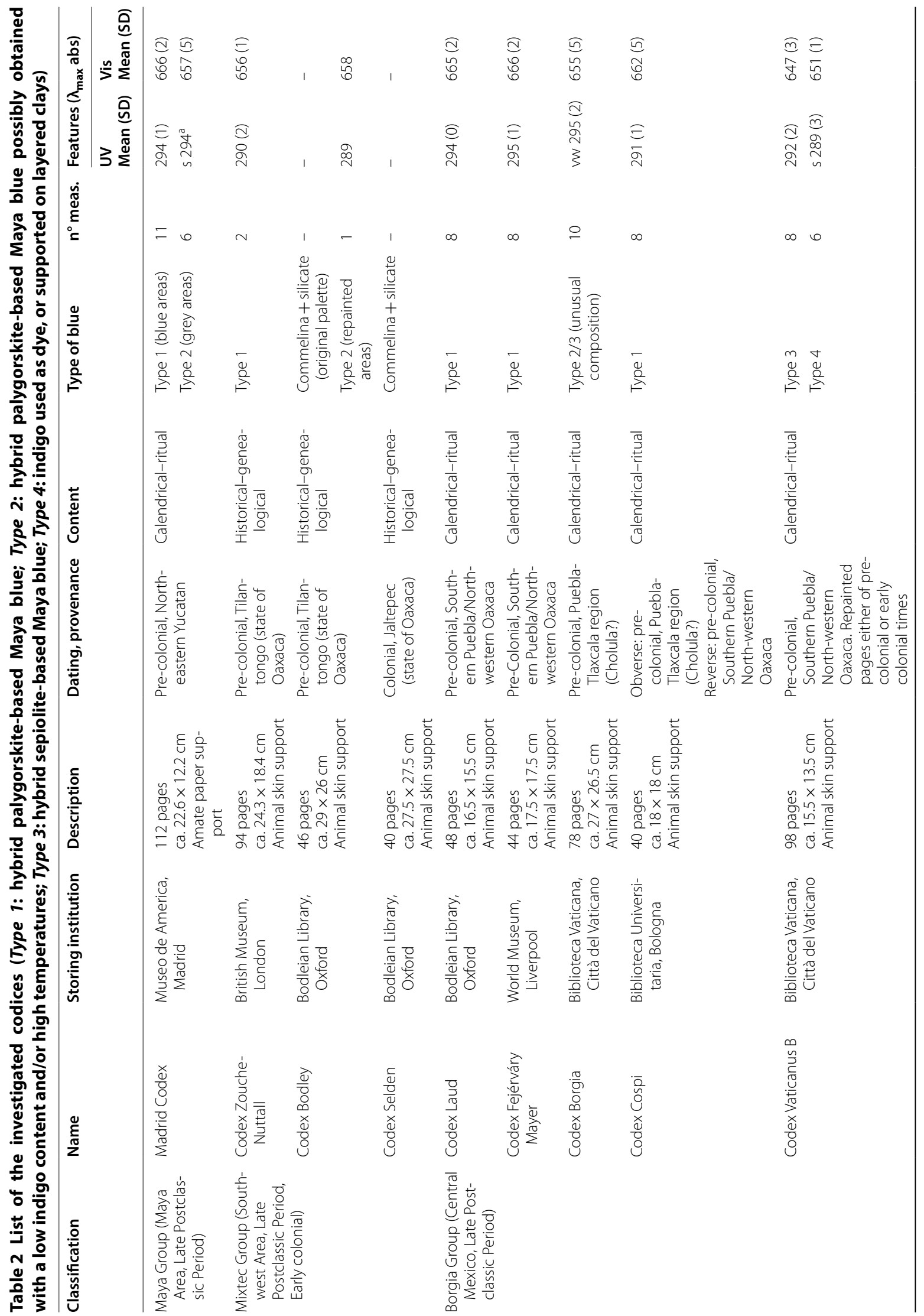




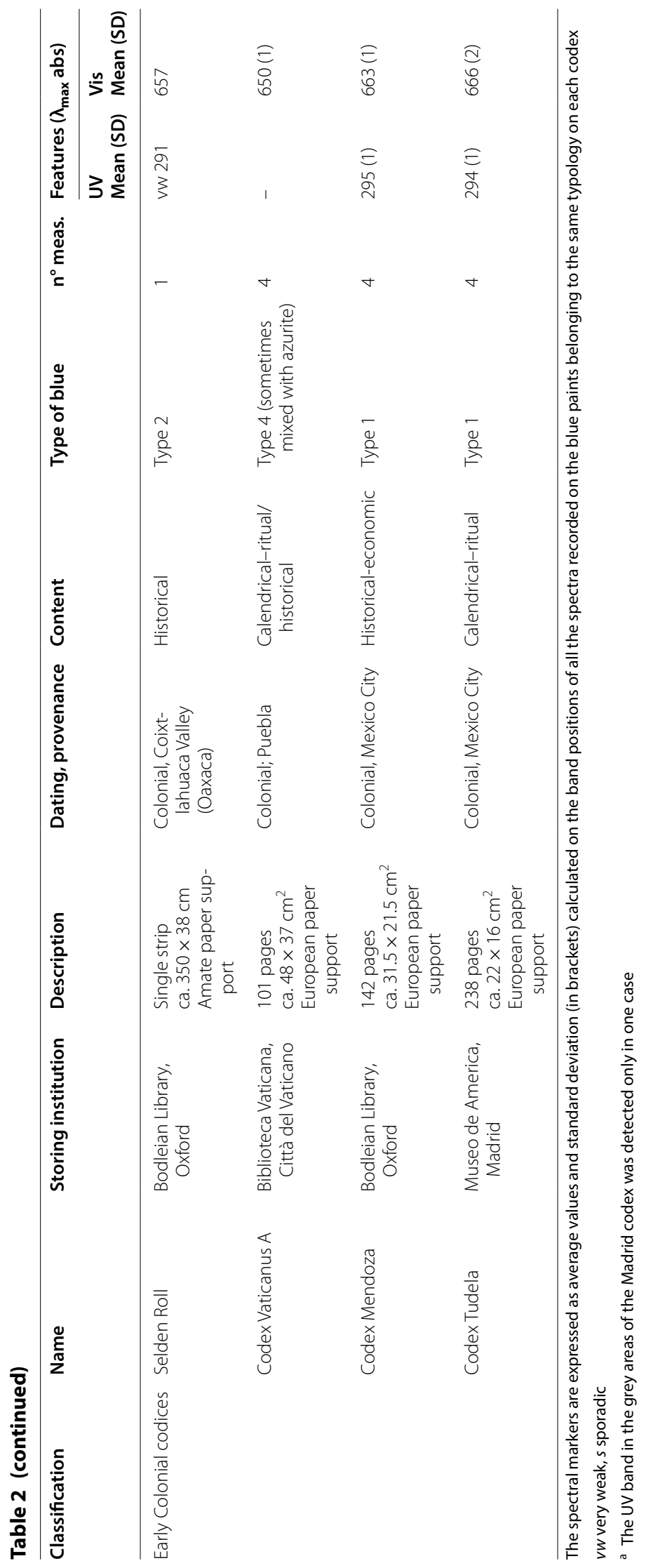


a

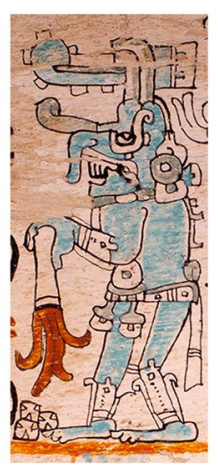

b

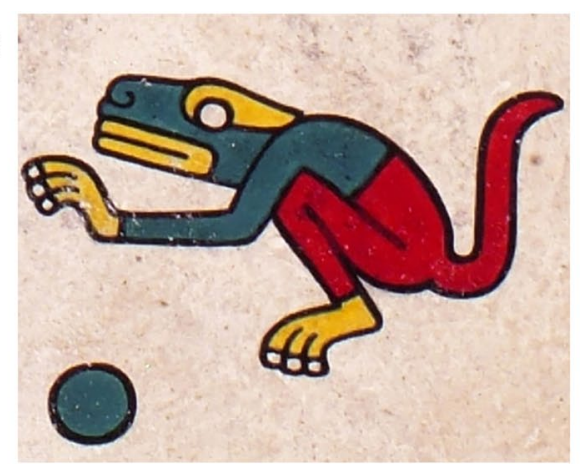

d

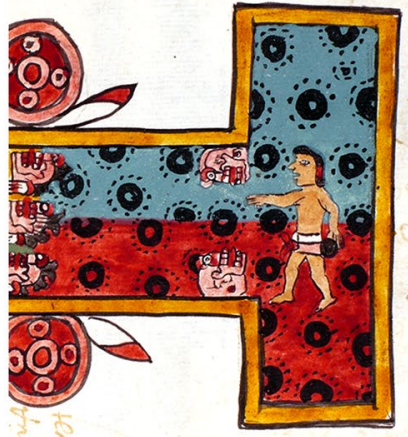

e

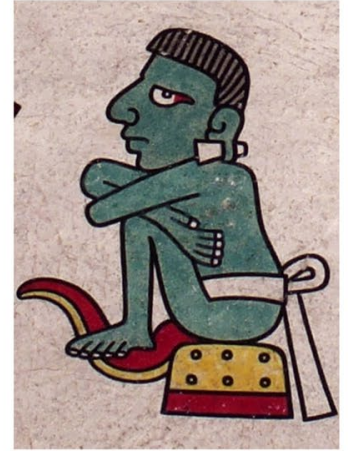

c

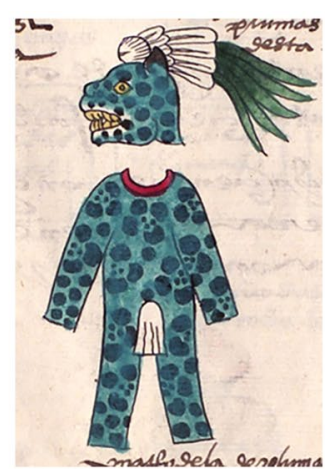

f

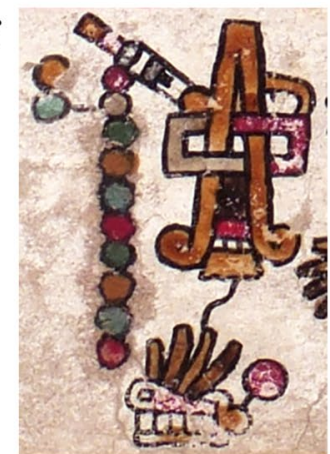

i

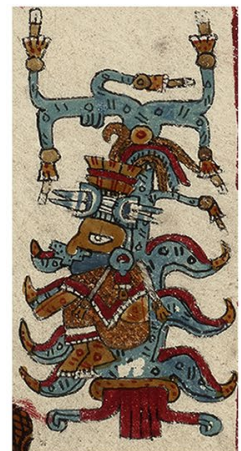

8 g

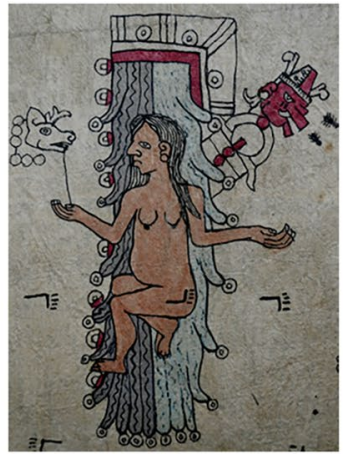

h

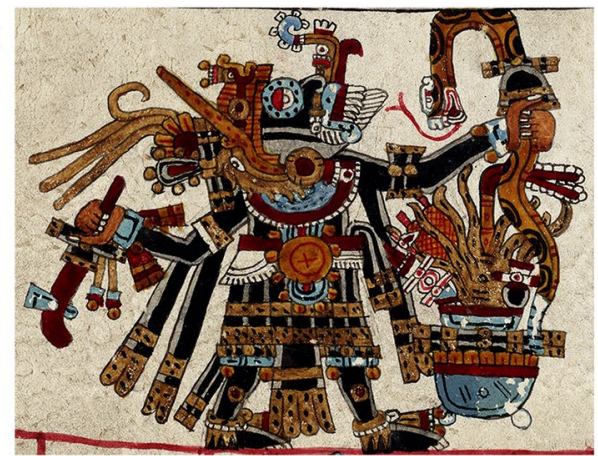

Fig. 6 Details of the codices pages showing the four different typologies of blue paints. a Codex Madrid, Type 1 in blue areas, Type 2 in grey areas; $\mathbf{b}$ Codex Fejérváry-Mayer, Type 1; c Codex Mendoza, Type 1; d Codex Tudela, Type 1; e Codex Laud, Type 1; f Codex Bodley, Type 2; g Selden Roll, Type 2; $\mathbf{h}$, i Codex Vaticanus B, Type 3 in light blue areas, Type 4 in dark blue areas

have been used with the purpose of getting deep insight into the codices painting technology. Indeed, the use of UV-vis spectroscopy provided a rough classification of the blue painting materials into two main groups: indigobased pigments, object of this study, and paints probably obtained from the flowers of Commelina coelestis (in two codices indicated in Ref. [6]) which will be discussed elsewhere. In addition, UV-vis spectroscopy gave also indications about the synthesis parameters used in the production of the indigo-based pigments supported by reflection FT-IR which allowed unequivocally for identification of the inorganic component in the majority of the blue-painted areas.
On the basis of the outcomes of the reference samples, a closer examination of the reflectance spectra collected on the codices allowed to classify the indigo-based blues in four subclasses:

i. proper hybrid palygorskite-based Maya blue (type 1, Fig. 7a);

ii. hybrid palygorskite-based Maya blue possibly obtained with a low indigo content and/or high heating temperatures (type 2, Fig. 7b);

iii. hybrid sepiolite-based Maya blue (type 3, Fig. 7c);

iv. indigo used as dye, or supported on layered clays (type 4, Fig. 7d). 

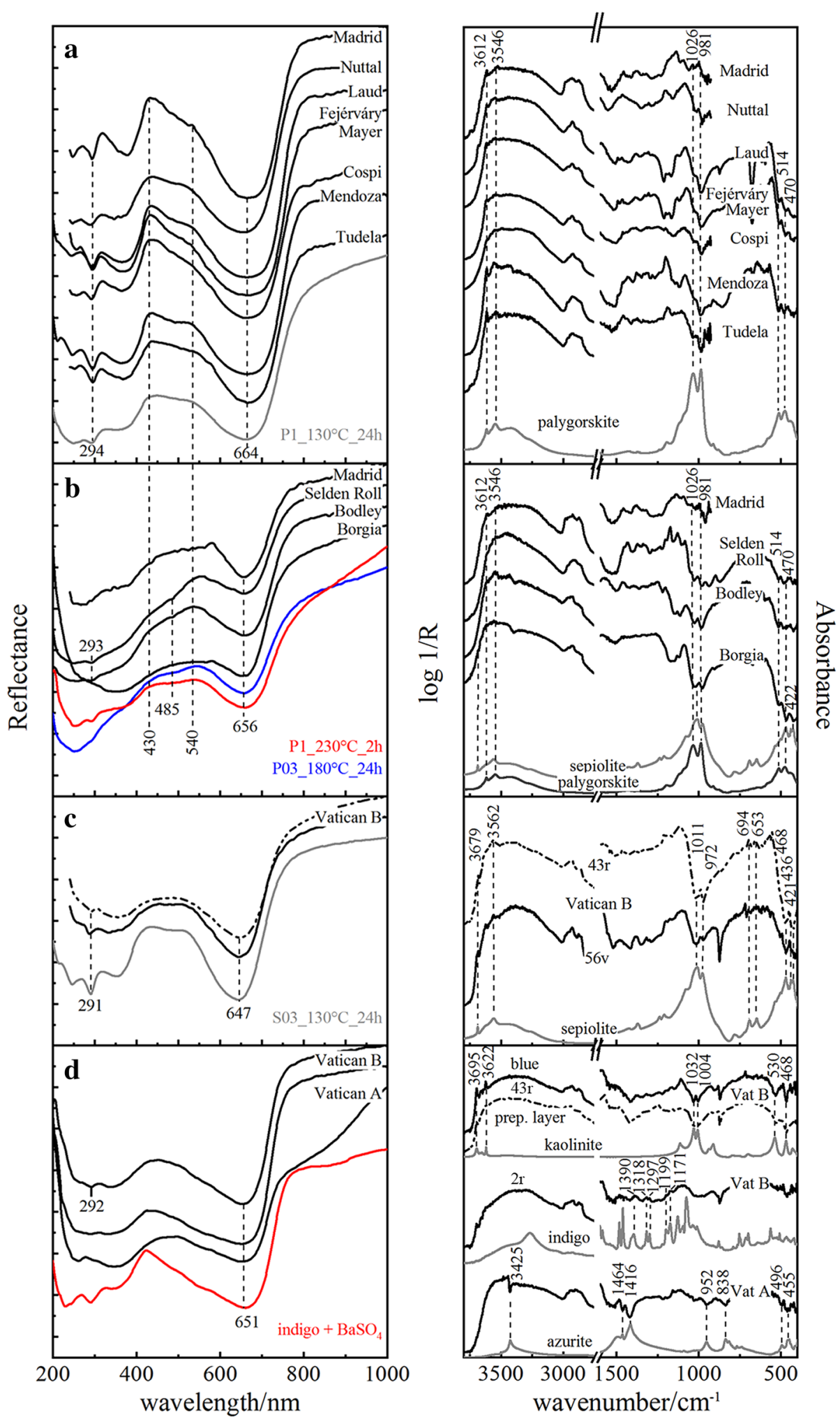

Fig. 7 UV-Vis reflectance and FT-IR spectra collected on real cases in comparison with reference standard samples (a Type 1, b Type 2, c Type 3, d Type 4). Spectra are vertically translated for clarity (P1: palygorskite-based Maya blue containing 1 wt\% indigo; P03: palygorskite-based Maya blue containing 0.3 wt $\%$ indigo; S03: sepiolite-based Maya blue containing 0.3 wt $\%$ indigo) 
The spectral markers reported hereinafter (i.e. position of UV and visible bands) are expressed as average values and standard deviation (in brackets) which have been calculated on the band positions of all the spectra recorded on the blue paints belonging to the same subclass.

Not surprisingly, palygorskite-based Maya blue (type 1) was clearly the blue pigment of choice in most of the codices (i.e. Codices Madrid, Nuttall, Laud, FejervaryMayer, Cospi, Tudela). Indeed, the reflectance profiles (some examples are reported in Fig. 7a) share a common colour band at 664 (4) $\mathrm{nm}$ and the weak absorption feature at 294 (2) nm, which allow the unambiguous identification of this type of hybrid pigment. Similarly to that observed in replicas obtained by changing the heating temperature, a closer observation of UV-vis spectra revealed that two slightly different shades of Maya blue are present: a bluish one and a greenish one, that can be classified by taking into account the reflection properties in the $400-540 \mathrm{~nm}$ range and the colorimetric parameters. In the reflectance spectra reported in Fig. 8c, the presence of a maximum around $540 \mathrm{~nm}$ accounting for the greenish hue of some of the paints can be easily noticed. Similar spectral changes occur in the reflectance profiles of palygorskite-based replica showed in Fig. 2 with the rise of temperature. At the same time, the colorimetric parameters in Fig. 8d are clearly clustered in two separated groups, with those classified as greenish having a higher contribution from the $b^{*}$ value. The greenish paints are characterised by $a^{*}, b^{*}$ values similar to the laboratory samples prepared with $1 \mathrm{wt} \%$ indigo heated at $160 / 180{ }^{\circ} \mathrm{C}$ (see Fig. 2b).

Only on a restricted number of codices (blue areas of Selden roll, Bodley and Borgia and grey areas of Madrid Codex) the analysis reveals the presence of an indigobased pigment with unusual optical properties (type 2). A representative selection of spectra in Fig. $7 \mathrm{~b}$ is indeed characterised by a weak absorption band at about 656 (4) $\mathrm{nm}$ (whose shape and position suggest the presence of palygorskite as inorganic component), and sporadic presence of a weak UV absorption band. In addition, an increased absorption in the range $400-540 \mathrm{~nm}$, resulting in a reflection maximum at about $540 \mathrm{~nm}$, accounts for the dull greenish hue observed. These evidences suggest a modified synthesis procedure for obtaining Maya blue, possibly involving the use of an initial indigo-clay mixture with a low concentration of indigo, and/or higher heating temperatures, as indicated by the comparison with reference spectra reported in Fig. 7b. Both reference spectra of indigo at $0.3 \mathrm{wt} \%$ heated at $180{ }^{\circ} \mathrm{C}$ and indigo at $1 \mathrm{wt} \%$ heated at $230{ }^{\circ} \mathrm{C}$ have a weak absorption band around $656 \mathrm{~nm}$; both show also an increased reflection maximum at about $540 \mathrm{~nm}$. As already pointed out in [4], unheated mixture with very low indigo cannot be completely disregarded, although the spectral shape in the $400-540 \mathrm{~nm}$ is less comparable than the one of heated samples.

Accordingly, reflection FT-IR spectra in type 1 and 2 show always the signals of palygorskite. Spectral profiles in Codices Madrid, Nuttall, Bodley, Laud, FejervaryMayer, Borgia, Cospi, Tudela and Selden Roll all share common features of palygorskite at ca. 470, 514, 981 and $1026 \mathrm{~cm}^{-1}$ attributed to $\mathrm{Si}-\mathrm{O}$ vibrations and at ca. 3546 and $3612 \mathrm{~cm}^{-1}$ ascribable to $\mathrm{O}-\mathrm{H}$ stretching [53] (examples are shown in Fig. 7a, b). Some spectral features appear inverted or slightly shifted when compared to the spectrum in transmission mode, due to surface effects connected with the reflection mode. It is worth to report that $\mathrm{Si}-\mathrm{O}$ stretching signals of blue and grey areas collected with the chalcogenide fibre optic set-up (see "Materials and methods") are sometimes noisy close to the spectral range cut-off.

An interesting case was observed on Codex Borgia, where an unusual mixture of palygorskite and possibly sepiolite was found in the greyish blue areas. Despite the interpretation of FT-IR reflection profiles can be sometimes challenging due to spectral distortions, in the spectrum reported in Fig. 7b the presence of the spectral features of both clay minerals can be highlighted. In comparison with palygorskite and sepiolite reference spectrum in transmission mode (dark grey and grey lines), the reflectance profile reported as example shows intermediate wavenumbers position for the $\mathrm{Si}-\mathrm{O}$ stretching bands at ca. 978 and $1023 \mathrm{~cm}^{-1}$. In the $\mathrm{Si}-\mathrm{O}$ bending region, the band at ca. $467 \mathrm{~cm}^{-1}$ is a common trait of both clay minerals while the ones at ca. 422 and $516 \mathrm{~cm}^{-1}$ are respectively attributed to sepiolite and palygorskite. Finally, in the $\mathrm{OH}$ stretching vibrations region, the weak band at $3546 \mathrm{~cm}^{-1}$ can be ascribed to palygorskite while the one at higher wavenumbers (shoulder, $3685 \mathrm{~cm}^{-1}$ ) to sepiolite. Reference Maya blue mock samples obtained by adding indigo to a mixture of palygorskite and sepiolite in the same weight amounts, are characterised by optical properties close to the ones of sepiolite-based hybrids (not shown). This result suggests that on Codex Borgia the mixture is rich in palygorskite.

While the painting style of Codex Vatican B is quite uniform, the colour palette is wide and complex, and this complexity is also reflected on the colour materiality of the blue paints.

UV-vis profiles in some of these areas (Fig. 7c, pages $43 \mathrm{r}$ and $56 \mathrm{v}$ ) resemble those of the reference sepiolitebased hybrid (type 3), showing characteristic absorption bands at 291 (2) and 647 (3) nm. As previously discussed in the "Results" section, the sepiolite-based hybrid has a blue-shifted position of both UV and visible band with 

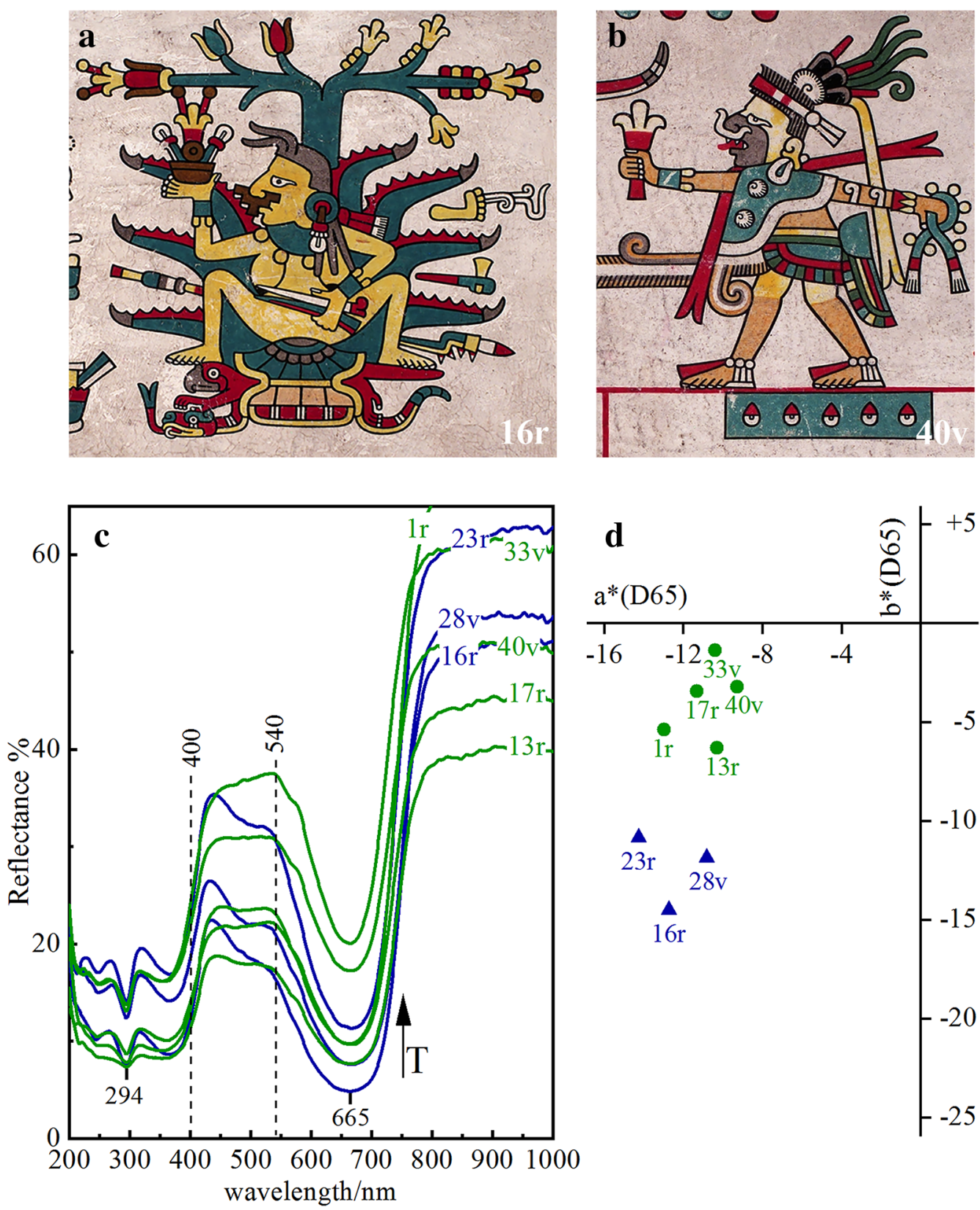

Fig. 8 a, b Examples of a bluish paint from page 16r and a greenish paint from page 40v of Codex Laud. c UV-Vis Reflectance spectra recorded on bluish and greenish areas of Codex Laud. The dashed lines indicate the reflection properties in the 400-550 nm range which have been considered for the classification of the bluish vs. greenish hue. $\mathbf{d}$ Projection in the $\mathrm{a}^{*} \mathrm{~b}^{*}$ space of the colorimetric measurements recorded on the same areas

respect to the palygorskite-based hybrid. Among the synthesized sepiolite-based samples, that containing indigo at $0.3 \mathrm{wt} \%$ heated at $130{ }^{\circ} \mathrm{C}$ is the one having comparable features to the spectra collected on Codex Vatican B (shape of both reflection maxima in the $400-550 \mathrm{~nm}$ range and location of the absorption bands).

Consistently, infrared signals related to sepiolite were detected in the codex. The example presented in Fig. 7c shows bands of $\mathrm{Si}-\mathrm{O}$ bending and stretching modes (inverted by reststrahlen effect) at ca. 421, 436, 468, 653, 694, 972 and $1011 \mathrm{~cm}^{-1}$ and $\mathrm{O}-\mathrm{H}$ vibrational transitions at ca. 3562 and $3679 \mathrm{~cm}^{-1}$ [53].

UV-Vis analysis suggests the presence of indigo (type 4 ) as colouring matter in other blue areas of Codex Vaticanus B. Examples from pages $2 \mathrm{r}$ and $43 \mathrm{r}$ are reported in Fig. $7 \mathrm{~d}$ and compared with the reference spectrum of 
indigo diluted in barium sulphate. The visible band at 651 (1) $\mathrm{nm}$ is in fact broader and asymmetrical if compared to that in either palygorskite-based or sepiolite-based hybrid pigments (see the different spectral features in Figs. 2a and 3a). Furthermore FT-IR analysis conducted on the same pages reveals bands ascribable to indigo (2r) and to kaolinite (43r). In the first case, the detection of indigo (bands at 1171, 1199, 1297, 1318 and $1390 \mathrm{~cm}^{-1}$ ) [58] and the absence of signals attributed to an inorganic substrate, support the UV-vis results and suggest the use of indigo as pure dye. In the second case, although kaolinite is one of the components of the preparatory layer of the codex, the stronger signals detected on some blue areas, suggests a mixture of the clay with the blue dye. The infrared spectrum in Fig. $7 \mathrm{~d}$ is characterised by signals at ca. 468, 530, 1004, 1032 ( $\mathrm{Si}-\mathrm{O}$ stretching and bending modes), 3622 and $3695 \mathrm{~cm}^{-1}$ (O-H vibrations) [61]. It is worth to mention that this clay is not a suitable substrate for obtaining a stable Maya blue pigment upon heating [22], but it may have been added to indigo to achieve a lighter shade. It is also important to report that in this last example (i.e. page 43r, indigo supported on kaolin), the features of the band responsible for the colour in the UV-Vis spectra indicates the presence of indigo not intercalated, although a weak absorption band at $291 \mathrm{~nm}$ (Fig. 7d), generally evident only in Maya blue samples, is observed.

The last example of blue paint here reported was seen on Codex Vaticanus A, and it belongs to the type 4 subclass. Interestingly UV-Vis reflectance indicates indigo as a dye, not as a hybrid, mixed with another blue pigment as indicated by the slope in the spectrum after $750 \mathrm{~nm}$, then firmly identified as azurite by means of FT-IR analysis (Fig. 7d, infrared bands at 455, 496, 838, 952, 1416, 1464 and $3425 \mathrm{~cm}^{-1}[62,63]$. The blue inorganic pigment was identified in other areas of the same codex but in this specific case the multi-technique approach allowed mixture of the two blue components to be identified.

\section{Discussion}

The analyses carried out on blue colours of pre-Hispanic and colonial Mesoamerican codices do contribute to a better understanding of the compositional variability of these painting materials and, when addressed in a comparative perspective, of the existence of different technological traditions of colour preparation in ancient Mesoamerica [64, 65]. Actually, a great variability has already been ascertained in Maya blue colours used on other media in the Maya area, where indigo was supported not only on tubular clays such as palygorskite (the "standard" and most efficient support for Maya blue) and sepiolite, but also-even if more rarely-on planar clays such as kaolinite, montmorillonite and saponite.
Concerning pictorial manuscripts, it is not surprising that palygorskite-based Maya blue has been detected on the Maya Madrid Codex (where it is used for both a blue, type 1 and a grey hue, type 2), as well as on the only other scientifically studied Maya manuscript, Codex Grolier $[4,10]$. Since Maya blue was introduced in Southwestern and Central Mexico at least since the Epiclassic period (post $600 \mathrm{AD}$ ), it would have been expectable to find it also on the Postclassic manuscripts from these regions, but actually the scientific results here discussed provide a far more complex picture than expected, since proper Maya blue seems to have had a quite restricted usage.

Within the "Borgia Group" codices of Central Mexico, it was used only on three manuscripts probably painted in the Southern Puebla/Western Oaxaca (Tehuacán?) area (Laud, Fejérváry-Mayer and Cospi verso); Codex Borgia, on the other hand, uses a hybrid colour where indigo was probably intercalated on a mixture of palygorskite and sepiolite (type 2/3). The original (pre-Hispanic) palette of Codex Vaticanus B, instead, includes two different kinds of Maya blue, where indigo is supported either on sepiolite (type 3) or on kaolinite (type 4, not proper Maya blue because the planar structure of the clay does not allow the intercalation of indigo into the inorganic framework); the repainted pages of the same manuscript, whose dating to the pre-Hispanic or early colonial period is uncertain, show the use of both the indigo-sepiolite hybrid type 3 and of pure indigo type 4 .

Proper Maya blue (type 1) was also used on few Mixtec manuscripts from Oaxaca (Zouche-Nuttall, Colombino, and Bodley) [6, 64]; interestingly, Codex Zouche-Nuttal is a Mixtec manuscript showing strong similarities, both stylistic and technological, with the Laud/FejérváryMayer/Cospi verso (subgroup of the Borgia Group). The case of Codex Bodley is extremely interesting since the use of type 2 on the manuscript is limited to two repainted numeral points on page 14 (one blue and one painted with a Maya blue-based green). The blue areas of the codex's original palette are instead painted with a hybrid colour composed by commelina and silicate, very similar to the one used on another Mixtec manuscript, Codex Selden, painted in colonial times but following purely pre-colonial practices.

In the recent literature on Maya blue, scholars have been discussing if Maya blue was only used in ritual contexts or also in more mundane ones [66-68]. The objects of our investigation are probably not completely adequate to fully answer this question. Indeed, the usage of Maya blue on colonial codices such as Codex Mendoza, surely not intended to be used in indigenous ritual contexts, testify that the precious blue pigment was also used on mundane items. On the other hand, it is also true that such manuscripts, 
even when not of a ritual kind, were clearly perceived as highly precious artefacts, being anyway endowed with some kind of ceremonial aura. This said, the detected patterns of distribution of Maya blue, rather than reflecting a ritual/mundane dichotomy, suggests that they depended on differential access to the trade networks through which Maya blue circulated in Postclassic Mesoamerica. Indeed, the abovementioned distribution of blue colours suggests that only specific areas of Central and Southwestern Mexico had easy access to proper Maya blue, or its main ingredient palygorskite, from the Maya area. In fact, the two known sources of palygorskite are in the Yucatan peninsula; actually, we do not know if Maya blue was imported in Central and Southwestern Mexico as an already prepared colour or if it was locally produced with imported materials; the study of epiclassic mural paintings in Cacaxtla (Tlaxcala) suggests that the latter was the case [69]. On the other hand, the ample use of sepiolite and, even in a lesser degree, of kaolinite suggests that Central and Southwerstern artisans were experimenting with locally available materials, maybe due to difficulties in obtaining paligorskite, to produce a colour similar, but not identical, to proper Maya blue. The usage of commelina (matlalin in Náhuatl) instead of indigo as a component of hybrid blue colours seems to confirm these technological experimentations.

In early colonial times the use of proper Maya blue seems to have been more widespread, since it has been detected on various manuscripts such as codices Mendoza, Tudela, Borbonicus, Florentinus, Huamantla, Selden Roll, Beinecke Map, and maybe on other manuscripts such as Codex Badianus and some maps attached to the Relaciones Geográficas [6, 9, 11, 31, 64, 70-74]. Unfortunately the lack of pre-Hispanic manuscripts from the Basin of Mexico prevents us to know if in that region proper Maya blue was used for painting codices in pre-colonial times, but evidences of its usage on other media indicate that painters residing at the very earth of the Aztec empire had access to Maya blue or its ingredients. Anyway, the use of proper Maya blue on colonial manuscripts both from the Basin of Mexico and more peripheral areas suggests that the changes introduced by the Spanish conquest in the trading patterns made the precious colour more easily available in different Mesoamerican regions. At the same time, the use of commelina not as an ingredient of an hybrid colour but as a simple dye superimposed on a proper Maya blue layer on Codex Borbonicus [11] suggests that technological experimentation was still going on in early colonial times, a period when colours previously not used for painting codices, such as azurite, were further enriching the palette of colonial indigenous painters [75].

\section{Conclusions}

Maya blue from 13 codices (eight pre-colonial and five colonial) was investigated by the European MOLAB facility through a non-invasive multi-technique approach. The valuable set of non-invasive data was interpreted on the basis of a systematic study on model samples prepared ad hoc varying the nature of the clay, indigo-clay ratios, heating temperatures and duration. UV-Vis reflectance spectra, recorded on these laboratory mock-ups, allowed to define specific spectral markers to (i) discriminate indigo from Mayablues (both palygorskite-based and sepiolite-based), (ii) distinguish palygorskite-based Maya blue from the sepiolite-based one and (iii) inform about synthesis conditions such as temperature and indigo-clay ratios.

On the basis of the study on the laboratory samples, four different types of indigo-based paints were detected in the 13 codices investigated. These findings allowed to shed light on Maya blue production, the famous Mesoamerican pigment considered the first nanocomposite material of the history and, more generally, on Mesoamerican codices painting technology including the interrelations among different Mesoamerican cultures, the possible trade of materials and traditions, and the related historical cultural implications.

\section{Supplementary information}

Supplementary information accompanies this paper at https://doi. org/10.1186/s40494-019-0345-z.

Additional file 1. Raman and colorimetric analysis of mock samples.

\section{Abbreviations}

DFT: density functional theory; TD-DFT: time-dependent density functional theory; FT-IR: Fourier-transform infrared; CCD: charged-coupled device; CPCM: conductor-like polarizable continuum model; DMF: dimethylformamide; NIR: near infrared; ind: indigo; P1: palygorskite-based Maya blue containing 1 wt\% indigo; P03: palygorskite-based Maya blue containing 0.3 wt\% indigo; S03: sepiolite-based Maya blue containing 0.3 wt $\%$ indigo.

\section{Acknowledgements}

The research has been supported by Horizon 2020 Programme of the EU (IPERION CH Grant Agreement n. 654028). In situ non-invasive campaigns were carried out by the European MOLAB facility made accessible thanks to the support of the EU commission under the projects CHARISMA (FP7) and EUARTECH (FP6). Authors are grateful for the access to the data related to Maya blue analysis to the MOLAB users at the following institutions: British Museum (London), Biblioteca Universitaria (Bologna), Museo de America (Madrid), National Museums (Liverpool), Bodleian Library (Oxford), Biblioteca Apostolica Vaticana (Città del Vaticano). The following MOLAB researchers are acknowledged for their support during in situ analyses: F. Presciutti, C. Clementi, L. Cartechini, F. Gabrieli, C. Anselmi and N. Mancinelli. 


\section{Authors' contributions}

GC, CM and DB conceived the study. CG and DB drafted the paper. FR and AR contributed to the acquisition and analysis of the data. AA carried out DFT calculations. FR, AR, DD and AS were involved in the interpretation of the results and drafting/revising the manuscript. All authors read and approved the final manuscript.

\section{Funding}

The research has been supported by Horizon 2020 Programme of the EU (IPERION CH Grant Agreement n. 654028).

\section{Availability of data and materials}

The datasets used and/or analysed during the current study are available from the corresponding author on reasonable request.

\section{Competing interests}

The authors declare that they have no competing interests.

\section{Author details}

1 SMAArt c/o Department of Chemistry, Biology and Biotechnology, University of Perugia, Via Elce di Sotto 8, 06123 Perugia, Italy. ${ }^{2}$ CNR-ISTM (Istituto CNR di Scienze e Tecnologie Molecolari), Via Elce di Sotto 8, 06123 Perugia, Italy. ${ }^{3}$ CATS, Statens Museum for Kunst, Sølvgade 48-50, 1307 Copenhagen K, Denmark. ${ }^{4}$ Dipartimento di Storia Culture Civiltà, Università di Bologna, Piazza S. Giovanni In Monte 2, 40124 Bologna, Italy.

Received: 26 August 2019 Accepted: 11 December 2019 Published online: 02 January 2020

\section{References}

1. Miliani C, Rosi F, Brunetti BG, Sgamellotti A. In situ noninvasive study of artworks: the MOLAB multitechnique approach. Acc Chem Res. 2010:43(6):728-38.

2. Miliani C, Domenici D, Clementi C, Presciutti F, Rosi F, Buti D, et al. Colouring materials of pre-Columbian codices: non-invasive in situ spectroscopic analysis of the Codex Cospi. J Archaeol Sci. 2012;39(3):672-9.

3. Buti D. Multi-technique approach for the in situ study of ancient manuscripts. PhD Thesis. Università degli Studi di Firenze; 2012.

4. Buti D, Domenici D, Miliani C, García Sáiz C, Gómez Espinoza T, Jímenez Villalba F, et al. Non-invasive investigation of a pre-Hispanic Maya screenfold book: the Madrid Codex. J Archaeol Sci. 2014;42:166-78.

5. Buti D, Domenici D, Grazia C, Ostapkowicz J, Watts S, Romani A, et al. Further insight into Mesoamerican paint technology: unveiling the colour palette of the pre-Columbian Codex Fejérváry-Mayer by means of non-invasive analysis. Archaeometry. 2018;60(4):797-814.

6. Grazia C, Buti D, Cartechini L, Rosi F, Gabrieli F, Lladó-Buisán VM, et al. Exploring the materiality of Mesoamerican manuscripts by non-invasive spectroscopic methods: Codex Laud, Bodley, Selden, Mendoza and Selden Roll at the Bodleian Library. In: Jansen M, Lladó-Buisán VM, Snijders L, editors. Mesoamerican manuscripts. New Scientific Approaches and Interpretations. Brill; 2018. p. 134-59.

7. Domenici D, Buti D, Grazia C, Dupey García É, Romani A, Cartechini L, et al. Non-invasive chemical characterization of painting materials of Mesoamerican codices Borgia (Borg. mess. 1) and Vaticanus B (Vat. lat. 3773) of the Biblioteca Apostolica Vaticana. Miscellanea Bibliothecae Apostolicae Vaticanae, XXV, 2019. p. 201-28.

8. Zetina Ocaña S, Ruvalcaba Sil JL, Álvarez TF, Arenas Alatorre J, Yanagisawa S, Álvarez Icaza Longoria M, et al. Material study of the codex Colombino. In: Sgamellotti A, Brunetti BG, Miliani C, editors. Science and art: the painted surface. London: Royal Society of Chemistry; 2014. p. 120-46.

9. Zetina S, Falcón T, Arroyo E, Ruvalcaba Sil JL. The encoded language of herbs: material insights into the De la Cruz-Badiano codex. In: Wolf G, Connors J, Waldman LA, editors. Colors Between two Worlds. The Florentine Codex of Bernardino de Sahagún. Florence, Villa I Tatti: The Harvard University Center for Italian Renaissance Studies; 2012. p. 221-56.

10. Ruvalcaba Sil JL, Zetina S, Calvo del Castillo H, Arroyo E, Hernandez E, Van der Meeren M, et al. The Grolier codex: a non destructive study of a possible Maya document using imaging and ion beam techniques. Materials
Issues in Art and Archaeology VIII. vol. 1047. Materials Research Society; 2008. p. 299-306

11. Pottier F, Michelin A, Andraud C, Goubard F, Histace A, Lavédrine B. Noninvasive characterization of dye-based paints in prehispanic Mesoamerica: The colors of the Codex Borbonicus. Proceedings of Dyes in History \& Archaeology (DHA); 2015

12. Pottier F, Michelin A, Kwimang S, Andraud C, Goubard F, Lavédrine B. Macroscopic reflectance spectral imaging to reveal multiple and complementary types of information for the non-invasive study of an entire polychromatic manuscript. J Cult Herit. 2019;35:1-15.

13. Giorgi R, Chelazzi D, Magaloni Kerpel D. Unveiling the artistic technique of the Florentine Codex: when the old world and the new world met. In: Sgamellotti A, Brunetti BG, Miliani C, editors. Science and art: the painted surface. London: Royal Society of Chemistry; 2014. p. 147-69.

14. Zaman T, Howell D, Snijders L. Imaging Mexican codices, challenges and opportunities. In: Jansen M, Lladó-Buisán VM, Snijders L, editors. Mesoamerican manuscripts. New scientific approaches and interpretations. Brill; 2018. p. 380-95.

15. Reyes-Valerio C. De Bonampak al Templo Mayor: el azul maya en Mesoamérica. Coleccion America Nuestra. America antigua. 1993: 40.

16. Chiari G, Giustetto R, Carson YD. Azul maya: una maravillosa nanotecnología precolombina. Boletín de Monumentos Históricos. 2008;12:39-48.

17. López Austin A, García Quintana J. Historia general de las cosas de Nueva España. Consejo Nacional para la Cultura y las Artes; 2000.

18. Hernández F. Obras completas: Historia natural de nueva Espana. Universidad Nacional de México; 1959.

19. Dupey García É. The materiality of color in pre-Columbian codices: insights from cultural history. Ancient Mesoamerica. 2017:1-20.

20. Gettens RJ. Maya blue: an unsolved problem in ancient pigments. Am Antiq. 1962:27(4):557

21. Shepard AO, Gottlieb HB. Maya Blue: alternative hypotheses. Notes from a ceramic laboratory. 1962:43-64.

22. Van Olphen H. Maya blue: a clay-organic pigment? Science. 1966;154(3749):645-6.

23. Suárez M, García-Romero E. Advances in the crystal chemistry of sepiolite and palygorskite, vol. 3. 2011. p. 33-65.

24. Giustetto R, Seenivasan K, Bordiga S. Spectroscopic characterization of a sepiolite-based Maya Blue pigment. Periodico di Mineralogia. 2010;79:21-37.

25. Sánchez del Río M, Doménech A, Doménech-Carbó MT, Vázquez de Agredos Pascual ML, Suárez M, García-Romero E. The Maya blue pigment. In: Emilio G, Arieh S, editors. Developments in clay science, vol. 3. Amsterdam: Elsevier; 2011. p. 453-81.

26. Hubbard B, Kuang W, Moser A, Facey GA, Detellier C. Structural study of Maya Blue: textural, thermal and solid-state multinuclear magnetic resonance characterization of the palygorskite-indigo and sepiolite-indigo adducts. Clays Clay Miner. 2003;51(3):318-26.

27. Chiari G, Giustetto R, Ricchiardi G. Crystal structure refinements of palygorskite and Maya Blue from molecular modelling and powder synchrotron diffraction. Eur J Mineral. 2003;15(1):21-33.

28. Chiari G, Giustetto R, Druzik J, Doehne E, Ricchiardi G. Pre-columbian nanotechnology: reconciling the mysteries of the maya blue pigment. Appl Phys A. 2008;90(1):3-7.

29. Tilocca A, Fois E. The color and stability of Maya Blue: TDDFT calculations. J Phys Chem C. 2009;113(20):8683-7.

30. Polette-Niewold LA, Manciu FS, Torres B, Alvarado M Jr, Chianelli RR. Organic/inorganic complex pigments: ancient colors Maya Blue. J Inorg Biochem. 2007;101(11-12):1958-73.

31. Pottier F. Etude des matières picturales du Codex Borbonicus-Apport des spectroscopies non-invasives à la codicologie. PhD Thesis. Université de Cergy Pontoise (UCP); 2017

32. Doménech-Carbó A, Holmwood S, Di Turo F, Montoya N, Valle-Algarra FM, Edwards HG, et al. Composition and color of Maya Blue: reexamination of literature data based on the dehydroindigo model. J Phys Chem C. 2019;123(1):770-82.

33. Bernardino N, Constantino VRL, De Faria D. Probing the indigo molecule in Maya blue simulants with resonance Raman spectroscopy. J Phys Chem C. 2018;122(21):11505-15.

34. Reinen D, Köhl P, Müller C. The Nature of the Colour Centres in'Maya Blue' - the Incorporation of Organic Pigment Molecules into the 
Palygorskite Lattice. Zeitschrift für anorganische und allgemeine Chemie. 2004;630(1):97-103.

35. Manciu FS, Reza L, Polette LA, Torres B, Chianelli RR. Raman and infrared studies of synthetic Maya pigments as a function of heating time and dye concentration. J Raman Spectrosc. 2007;38(9):1193-8.

36. Sánchez del Río M, Boccaleri E, Milanesio M, Croce G, van Beek W, Tsiantos $C$, et al. A combined synchrotron powder diffraction and vibrational study of the thermal treatment of palygorskite-indigo to produce Maya blue. J Mater Sci. 2009;44(20):5524-36.

37. Torres LM. Maya blue: how the Mayas could have made the pigment. MRS Online Proceedings Library Archive. 1988;123.

38. Sánchez del Rio M, Martinetto P, Reyes-Valerio C, Dooryhee E, Suárez M. Synthesis and acid resistance of Maya Blue pigment. Archaeometry. 2006:48(1):115-30.

39. Hohenberg P, Kohn W. Inhomogeneous electron gas. Phys Rev. 1964;136(3B):B864.

40. Stratmann RE, Scuseria GE, Frisch MJ. An efficient implementation of time-dependent density-functional theory for the calculation of excitation energies of large molecules. J Chem Phys. 1998;109(19):8218-24.

41. Rassolov VA, Ratner MA, Pople JA, Redfern PC, Curtiss LA. 6-31G* basis set for third-row atoms. J Comput Chem. 2001;22(9):976-84.

42. Lee C, Yang W, Parr RG. Development of the Colle-Salvetti correlationenergy formula into a functional of the electron density. Phys Rev B. 1988;37(2):785.

43. Barone V, Cossi M. Quantum calculation of molecular energies and energy gradients in solution by a conductor solvent model. J Phys Chem A. 1998;102(11):1995-2001.

44. Cossi M, Rega N, Scalmani G, Barone V. Energies, structures, and electronic properties of molecules in solution with the C-PCM solvation model. J Comput Chem. 2003;24(6):669-81.

45. Frisch M, Trucks G, Schlegel H, Scuseria G, et al. Gaussian 09, Revision A.02. Wallingford: Gaussian, Inc.; 2016.

46. Serrano-Andrés $L$, Roos BO. A theoretical study of the indigoid dyes and their chromophore. Chem Eur J. 1997;3(5):717-25.

47. Pina J, Sarmento D, Accoto M, Gentili PL, Vaccaro L, Galvão A, et al. Excited-state proton transfer in indigo. J Phys Chem B. 2017;121(10):2308-18.

48. Weinstein J, Wyman GM. Spectroscopic studies on dyes. I. The association of indigo dyes in the solid phase 1. J Am Chem Soc. 1956;78(11):2387-90.

49. Monahan AR, Kuder JE. Spectroscopic differences between crystalline and amorphous phases of indigo. J Org Chem. 1972;37(25):4182-4.

50. Leona M, Casadio F, Bacci M, Picollo M. Identification of the pre-columbian pigment Maya blue on works of art by noninvasive UV-Vis and Raman spectroscopic techniques. J Am Inst Conserv. 2004;43(1):39.

51. Anokhin DV, Leshanskaya LI, Piryazev AA, Susarova DK, Dremova NN, Shcheglov EV, et al. Towards understanding the behavior of indigo thin films in organic field-effect transistors: a template effect of the aliphatic hydrocarbon dielectric on the crystal structure and electrical performance of the semiconductor. Chem Commun. 2014:50(57):7639-41.

52. Giustetto R, Wahyudi O. Sorption of red dyes on palygorskite: synthesis and stability of red/purple Mayan nanocomposites. Microporous Mesoporous Mater. 2011;142(1):221-35.

53. Frost RL, Locos OB, Ruan H, Kloprogge JT. Near-infrared and mid-infrared spectroscopic study of sepiolites and palygorskites. Vib Spectrosc. 2001;27(1):1-13.

54. Tsiantos C, Tsampodimou M, Kacandes GH, Sánchez del Río M, Gionis V, Chryssikos GD. Vibrational investigation of indigo-palygorskite association(s) in synthetic Maya blue. J Mater Sci. 2011;47(7):3415-28.

55. Miliani C, Romani A, Favaro G. A spectrophotometric and fluorimetric study of some anthraquinoid and indigoid colorants used in artistic paintings. Spectrochim Acta Part A Mol Biomol Spectrosc. 1998:54(4):581-8.

56. Giustetto R, Wahyudi O, Corazzari I, Turci F. Chemical stability and dehydration behavior of a sepiolite/indigo Maya Blue pigment. Appl Clay Sci. 2011;52(1):41-50.

57. Zhou J, Lu X, Boek ES. Confined water in tunnel nanopores of sepiolite: insights from molecular simulations. Am Miner. 2016;101(3):713-8.

58. Amat A, Rosi F, Miliani C, Sgamellotti A, Fantacci S. Theoretical and experimental investigation on the spectroscopic properties of indigo dye. J Mo Struct. 2011;993(1-3):43-51.
59. Rondao R, Seixas de Melo JS, Bonifacio VD, Melo MJ. Dehydroindigo, the forgotten indigo and its contribution to the color of Maya Blue. J Phys Chem A. 2010;114(4):1699-708.

60. Doménech A, Doménech-Carbó MT, Vázquez de Agredos-Pascual ML. From Maya Blue to "Maya Yellow": a connection between ancient nanostructured materials from the voltammetry of microparticles. Angewandte Chemie. 2011;50(25):5741-4.

61. Frost RL, Fredericks PM, Bartlett JR. Fourier transform Raman spectroscopy of kandite clays. Spectrochim Acta Part A. 1993:49(5-6):667-74.

62. Farmer VC. Infrared spectra of minerals. Mineralogical Society; 1974.

63. Miliani C, Rosi F, Daveri A, Brunetti B. Reflection infrared spectroscopy for the non-invasive in situ study of artists' pigments. Appl Phys A. 2012;106(2):295-307.

64. Domenici D, Miliani C, Sgamellotti A. Cultural and historical implications of non-destructive analyses on Mesoamerican codices in the Bodleian libraries. In: Jansen M, Lladó-Buisán VM, Snijders L, editors. Mesoamerican manuscripts. New scientific approaches and interpretations. Brill; 2018. p. 160-74.

65. Domenici D, Buti D, Miliani C, Brunetti BG, Sgamellotti A. The colours of indigenous memory: non-invasive analyses of pre-hispanic Mesoamerican codices. In: Sgamellotti A, Brunetti BG, Miliani C, editors. Science and art: the painting surface. London: Royal Society of Chemistry; 2014. p. 94-119.

66. Arnold DE, Branden JR, Williams PR, Feinman GM, Brown J. The first direct evidence for the production of Maya Blue: rediscovery of a technology. Antiquity. 2008;82(315):151-64.

67. Doménech A, Doménech-Carbó MT, Vidal-Lorenzo C, Vázquez de Agredos-Pascual ML. Insights into the Maya Blue technology: greenish pellets from the ancient city of La Blanca. Angewandte Chemie. 2012;51(3):700-3.

68. Doménech-Carbó A, Doménech-Carbó MT, Vidal-Lorenzo C, Vázquez de Agredos-Pascual ML, Osete-Cortina L, Valle-Algarra FM. Discovery of indigoid-containing clay pellets from La Blanca: significance with regard to the preparation and use of Maya Blue. J Archaeol Sci. 2014;41:147-55.

69. Magaloni Kerpel D. Materiales y técnicas de la pintura mural maya. In: (coord.) Staines Cicero L, editor. La pintura mural prehispánica en México. II, Tomo III Estudios. Mexico: UNAM; 2001. p. 135-206.

70. Haude ME. Identification of colorants on maps from the early colonial period of New Spain (Mexico). J Am Inst Conserv. 1998;37(3):240-70.

71. Wiedemann HG, Brzezinka K-W, Witke K, Lamprecht I. Thermal and Raman-spectroscopic analysis of Maya Blue carrying artefacts, especially fragment IV of the Codex Huamantla. Thermochim Acta. 2007:456(1):56-63.

72. Magaloni Kerpel D. Painters of the New World: The process of making the Florentine Codex. In: Wolf G, Connors J, Waldman LA, editors. Colors between two worlds. The Florentine Codex of Bernardino de Sahagún. Florence, Villa I Tatti: The Harvard University Center for Italian Renaissance Studies; 2012. p. 46-76.

73. Newman R, Derrick M, Miller ME, Mundy BE. Analytical report of the pigments and binding materials used on the Beinecke map. Painting a Map of sixteenth-century land, writing, and native rule, Beinecke Rare Book and Manuscript Library, Yale University. New Haven: Yale University Press; 2012. p. 91-100.

74. Pottier F, Michelin A, Tournié A, Goubard F, Histace A, Lavédrine B. Preliminary investigation on the Codex Borbonicus: macroscopic examination and coloring materials characterization. In: Dupey García É, Vázquez de Agredos-Pascual ML, editors. Painting the skin: pigments on bodies and codices in pre-Columbian Mesoamerica. Tucson: University of Arizona Press; 2019. p. 157-74.

75. Domenici D, Buti D, Miliani C., Sgamellotti A. Changing Colours in a Changing World. The Technology of codex painting in early colonial Mexico. In: Siracusano G, editor. Materia Americana The 'body' of Spanish American images (16th to mid-19th centuries). Mexico-Los Angeles: Conaculta-Getty Foundation (in Press).

\section{Publisher's Note}

Springer Nature remains neutral with regard to jurisdictional claims in published maps and institutional affiliations. 